Prepared for the U.S. Department of Energy

Under Contract DE-AC05-76RL01830

\title{
Applicability of the "Gallet Equation" to the Vegetation Clearances of NERC Reliability Standard FAC-003-2
}

H Kirkham

March 2012

Pacific Northwest

NATIONAL LABORATORY

Proudly Operated by Battelle Since 1965 



\title{
DISCLAIMER
}

This documentation was prepared as an account of work sponsored by an agency of the United States Government. Neither the United States Government nor any agency thereof, nor Battelle Memorial Institute, nor any of their employees, makes any warranty, express or implied, or assumes any legal liability or responsibility for the accuracy, completeness, or usefulness of any information, apparatus, product, or process disclosed, or represents that its use would not infringe privately owned rights. Reference herein to any specific commercial product, process, or service by trade name, trademark, manufacturer, or otherwise does not necessarily constitute or imply its endorsement, recommendation, or favoring by the United States Government or any agency thereof, or Battelle Memorial Institute. The views and opinions of authors expressed herein do not necessarily state or reflect those of the United States Government or any agency thereof.

\author{
PACIFIC NORTHWEST NATIONAL LABORATORY \\ operated by \\ BATTELLE \\ for the \\ UNITED STATES DEPARTMENT OF ENERGY \\ under Contract DE-AC05-76RL01830
}

Printed in the United States of America

Available to DOE and DOE contractors from the

Office of Scientific and Technical Information,

P.O. Box 62, Oak Ridge, TN 37831-0062;

ph: (865) 576-8401, fax: (865) 576-5728

email: reports@adonis.osti.gov

Available to the public from the National Technical Information Service,

U.S. Department of Commerce, 5285 Port Royal Rd., Springfield, VA 22161

ph: (800) 553-6847, fax: (703) 605-6900

email: orders@ntis.fedworld.gov

online ordering: http://www.ntis.gov/ordering.htm

$\sqrt{\square}$ This document was printed on recycled paper. 

PNNL-21220

\section{Applicability of the "Gallet Equation" to the Vegetation Clearances of NERC Reliability Standard FAC-003-2}

H Kirkham

March 2012

Prepared for U.S. Department of Energy under Contract DE-AC05-76RL01830

Pacific Northwest National Laboratory Richland, Washington 99352 


\section{Applicability of the "Gallet equation" to the vegetation clearances of NERC Reliability Standard FAC-003-2}

Harold Kirkham, PNNL

\section{Executive Summary}

NERC has proposed a standard to use to specify clearances between vegetation and power lines. The purpose of the rule is to reduce the probability of flashover to a calculably low level. NERC documentation of the rule ${ }^{1}$ has been examined, in particular

Exhibit A: Reliability Standard FAC-003-2 - Transmission Vegetation Management submitted for Approval

and

Exhibit I: Transmission Vegetation Management - FAC-003-2 Technical Reference Document

The method proposed for calculating the clearances is based on the results of testing for high-voltage line designs. An equation developed to relate the results of testing with rod-plane gaps to proposed tower window sizes has been adopted. ${ }^{2}$ While this equation is used in IEEE Standard $4^{3}$, and in the Transmission Line Reference book, ${ }^{4}$ it has not been shown to be applicable to vegetation clearances. In fact, various factors that can be found experimentally for line designs (gap constants, proximity effects) are just not known for vegetation. Realistically, there is no evidence that the statistics relating tower design parameters are useable with trees.

However, even if it is granted that the convenience of the method makes it worth using, inconsistencies are found in the NERC filing: Table ES-I (below) compares the information given in Exhibit A of the NERC filing with information found in Exhibit I of the filing.

\footnotetext{
${ }^{1}$ Available at http://www.ferc.gov/docs-filing/elibrary.asp by choosing Advanced Search and entering the number 20111221-5053 into the Accession Number window near the bottom of the page. Start the search by clicking Submit.

${ }^{2}$ G. Gallet, G. Leroy, R. Lacey, I. Kromer, General Expression for Positive Switching Impulse Strength Valid Up to Extra Long Air Gaps, IEEE Trans. Power Apparatus and Systems, Vol. PAS-94, No. 6, Nov./Dec. pp. 19891993, 1975.

${ }^{3}$ IEEE Standard Techniques for High Voltage Testing, Std 4-1995

${ }^{4}$ Transmission Line Reference Book - 345 kV and Above, Second Edition, Electric Power Research Institute, 1982.
} 
Table ES-I. Comparison of values in NERC filing

\begin{tabular}{cccc|cccc}
\multicolumn{3}{c|}{ Sparkover distance, Exhibit A, p 31 } & \multicolumn{4}{c}{ MVCD from Exhibit I, Table 1, p 44 } \\
\hline $\begin{array}{c}\text { Nom } \\
\text { voltage }\end{array}$ & $\begin{array}{c}\text { Max } \\
\text { voltage }\end{array}$ & $\begin{array}{c}\text { TOV } \\
\text { factor }\end{array}$ & $\begin{array}{c}\text { Clearance } \\
\text { at 3000 ft }\end{array}$ & $\begin{array}{c}\text { Nom } \\
\text { voltage }\end{array}$ & $\begin{array}{c}\text { Max } \\
\text { voltage }\end{array}$ & $\begin{array}{c}\text { TOV } \\
\text { factor }\end{array}$ & $\begin{array}{c}\text { Clearance } \\
\text { at 3000 ft }\end{array}$ \\
\hline 765 & 800 & 2.0 & $\mathbf{1 4 . 3 6}$ & 765 & 800 & 1.4 & $\mathbf{8 . 8 9}$ \\
500 & 550 & 2.4 & $\mathbf{1 1 . 0}$ & 500 & 550 & 1.4 & $\mathbf{5 . 6 6}$ \\
345 & 362 & 3.0 & $\mathbf{8 . 5 5}$ & 345 & 362 & 2.0 & $\mathbf{3 . 5 3}$ \\
230 & 242 & 3.0 & $\mathbf{5 . 2 8}$ & 230 & 242 & 2.0 & $\mathbf{3 . 3 6}$ \\
115 & 121 & 3.0 & $\mathbf{2 . 4 6}$ & 115 & 121 & 2.0 & $\mathbf{1 . 6 1}$ \\
\hline
\end{tabular}

In this table, the distance values are set in boldface. Values not used in the calculation are set in italic. ${ }^{5}$ The two sets of numbers are from the NERC filing (Exhibit A and Exhibit I). The distances differ significantly. It is certainly noteworthy that the numbers described as Minimum Vegetation Clearance Distance are about half the values shown as Sparkover Distance.

In general, the values given in each of the Exhibits for distances for EHV lines are smaller than the result of a direct application of Gallet would give. For example, the Sparkover Distance (Exhibit A, page 31) for a 765-kV line at less than $3000 \mathrm{ft}$ above sea level is $14.36 \mathrm{ft}$. The Gallet equation, with a Transient Overvoltage (TOV) of 2.0 p.u. and corrected for altitude (that is, with the same assumptions as the Exhibit), indicates a value of about $16.5 \mathrm{ft}$. The Minimum Vegetation Clearance Distance given for an 800-kV line at less than $3000 \mathrm{ft}$ above sea level is $8.89 \mathrm{ft}$ (Exhibit A, Table 2, page 26; and also Exhibit I, Table 1, page 44). The Gallet equation, with a TOV of 1.4 and corrected for altitude (again, the same assumptions as the Exhibits), indicates a value of $10.5 \mathrm{ft}$.

There is a wealth of information available from the research done for transmission line design. The Gallet equation arose during the performance of that research. It was a curve-fit, a way to reduce the amount of full-scale testing for the design of tower windows. The values of the voltage calculated by the equation are the values that are 50\% likely to result in a flashover. Because line designers do not design for such a high likelihood of flashover, the Gallet equation, if used, is not the end of the calculation.

The topic of the window size of towers of many designs has been extensively studied. However, there is not the same body of knowledge regarding vegetation clearance. Tower clearance values are nevertheless suggestive: the values for tower clearance for a line at $765 \mathrm{kV}$ in the Transmission Line Reference Book range from $14 \mathrm{ft}$ to over $18 \mathrm{ft}$. There is no reason to suppose that a tree could safely be allowed so much closer to a line (less than $9 \mathrm{ft}$ ) than a tower. The goal of a calculably low probability of flashover would not be met.

\footnotetext{
${ }^{5}$ The TOV values for the Exhibit I entries are not given in the Table in the Exhibit. They are found in the text on page 41.
} 


\section{Table of Contents}

Executive Summary .................................................................................................................

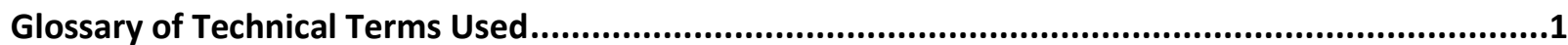

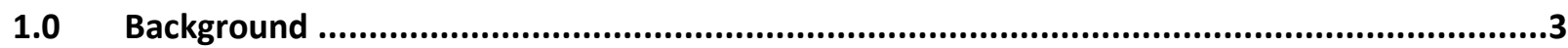

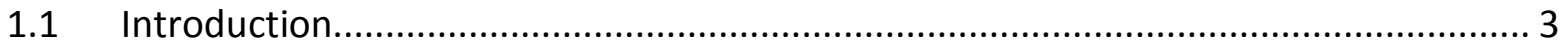

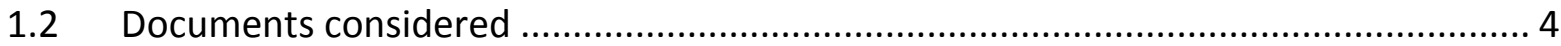

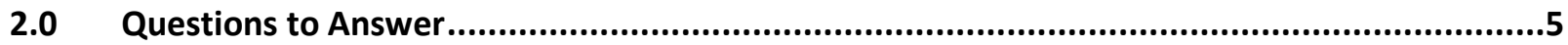

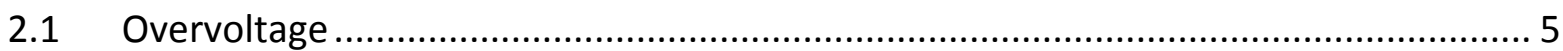

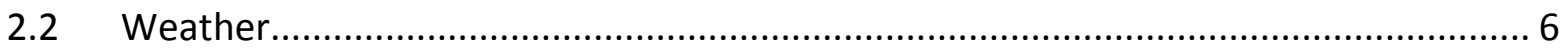

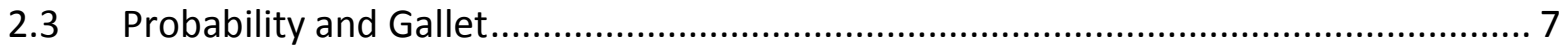

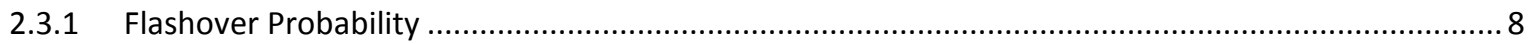

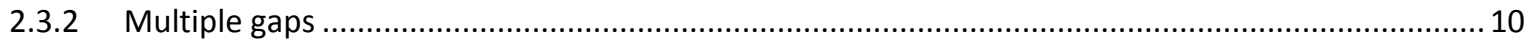

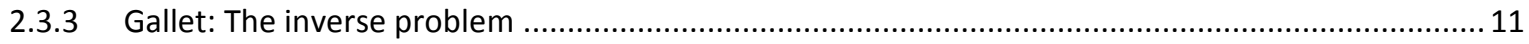

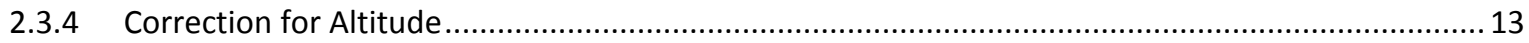

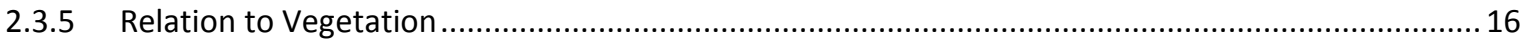

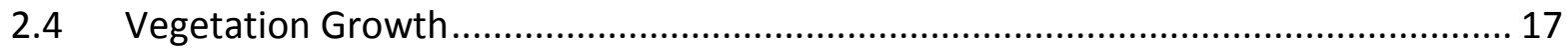

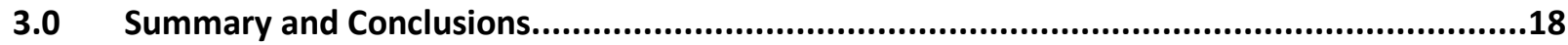

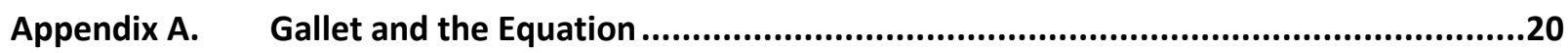

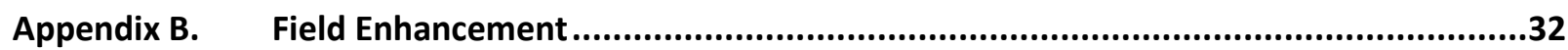

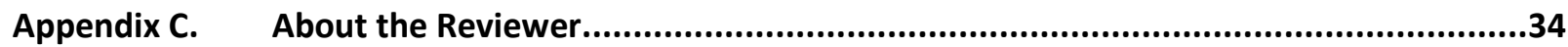




\section{List of Figures}

Figure 1 CFO voltage as a function of gap spacing (representative) ............................................ 9

Figure 2 Representative flashover probability data.................................................................. 9

Figure 3 Withstand probability for multiple gaps....................................................................... 11

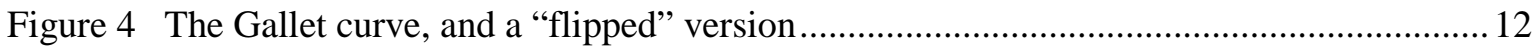

Figure 5 Effect of shape of rod-end on withstand capability...................................................... 17

Figure 6 US Electric Load and Population Growth, 1800 - 1970 ................................................. 20

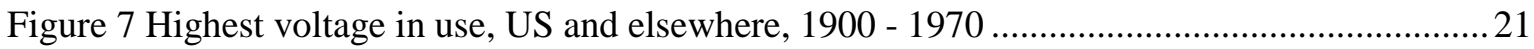

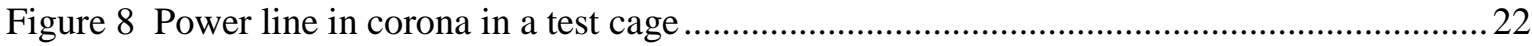

Figure 9 Representative impulse shape used in high voltage testing............................................ 25

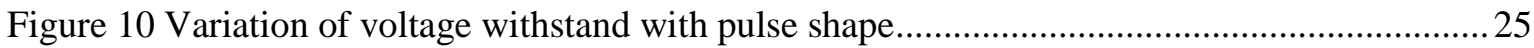

Figure 11 Breakdown probability for different impulse fronts...................................................... 26

Figure 12 CFO values for a variety of gap configurations ........................................................ 27

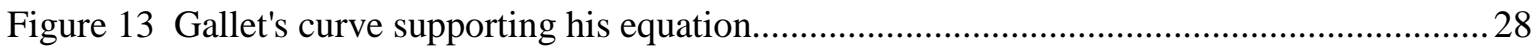

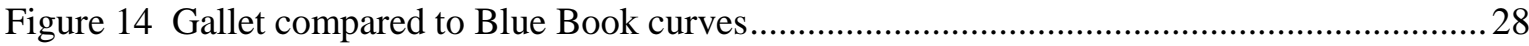

Figure 15 CFO curves from several laboratories, compared to Gallet and Paris with $\mathrm{k}=1.19$....... 29

Figure 16 Red Book curve of tower window and rod-plane results ........................................... 31

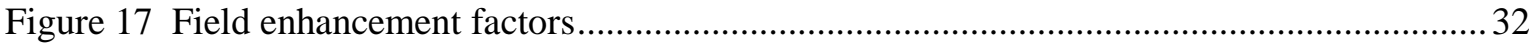

Figure 18 Wick on the winglet of an airplane ..................................................................... 33 


\section{Glossary of Technical Terms Used}

The field of high voltage engineering advances by communicating the results of its research. To be effective, the communication requires the use of language specific to the topic: the jargon of the technology.

The glossary below has been provided by the author with the intent of being a handy reference for the reader who is not familiar with the language of high voltage engineering. It is not a complete dictionary, but has been written to include only the jargon words that will be encountered in this report.

The glossary has been presented in a "logical" sequence rather than alphabetical. The entries are explained or commented on as seems appropriate to the author. (See, for example, the terms "flashover" and "sparkover.")

\begin{tabular}{|c|c|}
\hline $\begin{array}{l}\text { EHV } \\
\text { Extra High Voltage }\end{array}$ & $\begin{array}{l}\text { The term used for power lines operating in the range of } 345 \text { to } 765 \mathrm{kV} \text { phase to } \\
\text { phase. Such lines have been in operation since the 1960s. }\end{array}$ \\
\hline $\begin{array}{l}\text { UHV } \\
\text { Ultra High Voltage }\end{array}$ & $\begin{array}{l}\text { The term used for power lines operating above EHV levels. No lines of this } \\
\text { class are operational, though test facilities have been constructed in several } \\
\text { countries. }\end{array}$ \\
\hline insulation system & $\begin{array}{l}\text { An arrangement of insulation that serves to keep conductors at different } \\
\text { potentials apart, thereby preventing current flow. Such systems may involve } \\
\text { glass or ceramic materials, or organics such as paper, oil and various plastics, as } \\
\text { well as air or vacuum. }\end{array}$ \\
\hline impulse testing & $\begin{array}{l}\text { The testing of insulation systems by means of laboratory-generated impulses at } \\
\text { high voltage. The tests may be indoor or outdoor. For line-design purposes, } \\
\text { outdoor testing is considered more realistic and therefore preferred. }\end{array}$ \\
\hline rod-plane gap & $\begin{array}{l}\text { In testing high voltage insulation, a convenient configuration that produces } \\
\text { repeatable results is the rod to plane gap. The rod in question is circular in } \\
\text { section, and may have any orientation: the plane is orthogonal to it. The end of } \\
\text { the rod is customarily terminated by making it hemispherical. }\end{array}$ \\
\hline flashover & $\begin{array}{l}\text { The end of a process by which an insulation system fails and an electric current } \\
\text { flows. According to IEEE Std 4, the term should be reserved for the failure of } \\
\text { solid insulation, but it is in general use in the US applied to air breakdown as } \\
\text { well. }\end{array}$ \\
\hline sparkover & $\begin{array}{l}\text { The term that IEEE Std } 4 \text { reserves for the breakdown of gas insulation. The } \\
\text { term is used by European researchers in preference to flashover. }\end{array}$ \\
\hline withstand & $\begin{array}{l}\text { The capability of an insulation system to function as an insulator when a high } \\
\text { voltage is applied. }\end{array}$ \\
\hline $\begin{array}{l}\text { Gaussian (or } \\
\text { Normal) } \\
\text { distribution }\end{array}$ & $\begin{array}{l}\text { A probability distribution that has a characteristic bell-shaped curve. The center } \\
\text { of the distribution is the average value. The width of the curve gives an } \\
\text { indication of the spread of the things being represented. The distribution is } \\
\text { representative of many natural phenomena, and is mathematically well- } \\
\text { characterized. }\end{array}$ \\
\hline $\begin{array}{l}\text { overvoltage, } \\
\text { transient }\end{array}$ & $\begin{array}{l}\text { A short-term condition in which the voltage on a line exceeds its usual value. } \\
\text { The overvoltage may be due to a lightning strike (which can deposit charge } \\
\text { directly onto a conductor) or to switching (which can increase the voltage by }\end{array}$ \\
\hline
\end{tabular}




\begin{tabular}{|c|c|}
\hline overvoltage & $\begin{array}{l}\text { means of charge trapped on a line). Lighting is fast compared to switching } \\
\text { surges. On EHV and UHV lines, switching surges are larger in amplitude. }\end{array}$ \\
\hline risetime & $\begin{array}{l}\text { Broadly, the time taken for a pulse to reach its maximum value. Since pulses (or } \\
\text { surges) usually have the characteristic that they start gradually, and reach their } \\
\text { maximum value gradually, engineers usually define the risetime as the time } \\
\text { between } 10 \% \text { and } 90 \% \text { of the peak value. In high voltage testing, the time } \\
\text { between } 30 \% \text { and } 90 \text { is more commonly used. }\end{array}$ \\
\hline $\begin{array}{l}\text { critical flashover } \\
\text { voltage (CFO) }\end{array}$ & $\begin{array}{l}\text { The voltage at which a surge is } 50 \% \text { likely to cause a flashover. The word } \\
\text { critical means that the risetime of the surge is at the value known to result in the } \\
\text { lowest flashover voltage. In testing insulation systems with surges, the flashover } \\
\text { may occur before the peak value is reached, or (rarely) after the peak has been } \\
\text { passed. It customary to specify the voltage of the peak, nevertheless, rather than } \\
\text { the actual value at the instant of the flashover. }\end{array}$ \\
\hline tower window & $\begin{array}{l}\text { The space created by the structure of a tower, and through which the line } \\
\text { conductor passes. The window may be square in section, or may have more } \\
\text { sides. In an EHV or UHV line the conductor usually passes through the window } \\
\text { just below the center, and the insulators that support the conductor are given a } \\
\text { slightly longer gap than the air underneath. }\end{array}$ \\
\hline gap factor & $\begin{array}{l}\text { The ratio of the CFO of a test object to the CFO of a rod-plane gap for the same } \\
\text { spacing. For any given spacing, a rod-plane gap gives consistently the lowest } \\
\text { CFO voltage. Just how much stronger the gap of a tower window is can be } \\
\text { determined experimentally. Once the factor has been found for a certain shape } \\
\text { of window, it can be applied to other gap spacings of the same shape to } \\
\text { determine a corrected or adjusted CFO. }\end{array}$ \\
\hline
\end{tabular}




\section{Applicability of the "Gallet equation" to the vegetation clearances of NERC Reliability Standard FAC-003-2}

\subsection{Background}

The reliability of the electric power system has been adversely impacted on a number of occasions by trees growing too close to power lines. Under some conditions, there can be a flashover from the line to a tree, with the result that the protection system relays the line out. Under some circumstances, such an event can lead to cascading of other lines, and a large-scale blackout can ensue.

To guard against this possibility, NERC has issued a Reliability Standard (FAC-003-2) that requires that certain clearances be maintained from vegetation growing near to power lines. For the most part, the concern is lines operating above $200 \mathrm{kV}$. These are the ones most likely to be capable of cascading.

The clearances proposed by the Standard are calculated from an equation first presented in an IEEE paper, by a group led by G. Gallet. ${ }^{1}$ The equation has been termed "the Gallet equation.”

This report was commissioned by FERC's Office of Electrical Reliability. The scope of the study was analysis of the mathematics and documentation of the technical justification behind the application of the Gallet equation and the assumptions used in the technical reference paper. ${ }^{2}$ To put the analysis into perspective, are the assumptions made in the development of the Gallet Equation and their application in NERC-approved Reliability Standard FAC-003-2 reasonable to address the minimum distance requirements needed to avoid sustained vegetation-related outages?

The intent of the report is to consider the matter of the gap between the power line and the vegetation. This consideration does not include any allowance for factors such as conductor sag and wind displacement, which presumably can be separately calculated and added to the clearances needed.

\subsection{Introduction}

The setting of minimum clearances between power lines and trees involves several questions. For example,

- Are the clearances to be established for the purposes of power-frequency voltages only, or are the transient overvoltages that sometimes appear on power lines to be accounted for as well?

o If overvoltage is to be accounted for, at what level should it be set?

- Are the clearances to be applicable in all weather conditions, or just some?

- Since flashover is a rare event that is not entirely predictable, to what target level should the probability of flashover be reduced?

\footnotetext{
${ }^{1}$ G. Gallet, G. Leroy, R. Lacey, I. Kromer, General Expression for Positive Switching Impulse Strength Valid Up to Extra Long Air Gaps, IEEE Trans. Power Apparatus and Systems, Vol. PAS-94, No. 6, Nov./Dec. pp. 19891993, 1975.

${ }^{2}$ http://www.nerc.com/docs/standards/sar/Transmission_Veg_Man_Standard_FAC-003-2_ Technical_Ref_093011.pdf.
} 
The NERC Standard is based on decisions that indicate the following:

- The clearance values should allow for overvoltages

o A level of overvoltage has been assigned

- No particular weather conditions are required for the clearances to apply

- A flashover probability target has claimed $\left(10^{-6}\right.$, Exhibit I, page 41$)$

- Vegetation growth is not allowed for in these calculations (implying that a conservative value for the clearances should be used)

All these seem to be reasonable decisions. However, it is worthwhile to perform an analysis of the technical justification behind the Gallet equation, the mathematics and assumptions used in order to use the equation to calculate line to vegetation clearances.

\subsection{Documents considered}

Two parts of the NERC filing ${ }^{3}$ have been examined in this report. They are

Exhibit A: Reliability Standard FAC-00302 - Transmission Vegetation Management submitted for Approval

and

\section{Exhibit I:Transmission Vegetation Management - FAC-003-2 Technical Reference Document}

The first of these presents clearance values in the form of tables. For example, Table 2 (p 26) gives values for Minimum Vegetation Clearance Distance (MVCD) on a 765-kV line at up to $1000 \mathrm{ft}$ above sea level of $8.33 \mathrm{ft}$.

The pages in the NERC draft that follow the table of clearance values discuss factors such as overvoltage on power lines, and they also discuss something called the Gallet Equation. The document says that

The Gallet Equation also can take into account various air gap geometries. This approach was used to design the first $500 \mathrm{kV}$ and $765 \mathrm{kV}$ lines in North America.

In fact, the statement is only partly true. The equation of Gallet was not used to design the first $500-\mathrm{kV}$ lines or the first 765-kV lines, since these lines were designed and built many years before the Gallet equation came into being.

More detail on the Gallet equation is given in the second of the NERC documents, the Technical Reference to the first. The work of Gallet is placed in context and the background to his equation is given in Appendix A to this report, to which reference will be made in this assessment.

${ }^{3}$ Available at http://www.ferc.gov/docs-filing/elibrary.asp by choosing Advanced Search and entering the number 20111221-5053 into the Accession Number window near the bottom of the page. Start the search by clicking Submit. 
To determine the validity of the analysis in these documents this report considers below in more detail the questions asked above.

\subsection{Questions to Answer}

\subsection{Overvoltage}

The voltage on most US power lines is an alternating quantity that has a frequency very close to $60 \mathrm{~Hz}$. The waveshape is sinusoidal, and the system consists of three phases equally spaced in time. Under steady conditions, the voltage is described by the root-mean-square ${ }^{4}$ value of the voltage between two phases. For a line described as (say) $500 \mathrm{kV}$, the fact that there are three phases means that the rms voltage to ground of each one is $500 \div \sqrt{3}$, or about $289 \mathrm{kV}$. This voltage is established by the various transformers in the power system, by the various control devices and systems in use, and to a small extent by the load on the power system.

However, if the line is struck by lightning, it is possible for a higher voltage to be generated as a transient that appears superposed on the power-frequency voltage. Such a situation is described as an overvoltage, and various means are employed to limit the value of the overvoltage. The matter is one of economics. It costs more to insulate a line to a higher voltage, so if the overvoltage can be limited, the insulation cost can be controlled.

For power lines at or above $500 \mathrm{kV}$ or $765 \mathrm{kV}$, the overvoltage due to lightning is less of a problem than the overvoltage due to switching or other causes. ${ }^{5}$ These overvoltages are related to the line voltage (whereas lightning overvoltage is independent of line voltage per se, though it may depend on the parameters of a particular line design.) Consequently, the design of a power line at these voltage levels is concerned with including equipment capable of limiting the overvoltage.

An example of the overvoltage to be allowed for can be found in IEEE Std 516 - 2009. This is the IEEE Guide for Maintenance Methods on Energized Power Lines. It is shown in an Appendix of this IEEE Guide that the phase-phase voltage following reclosing a tripped line can exceed 4 times the normal line voltage. However, the line-ground overvoltage is lower, and is typically held to be no more than a factor of $2 .^{6}$

It must be noted that the calculated peak overvoltage is quite dependent on system conditions (it may be reduced by corona in bad weather, for example, or increased with certain loads). The value to be used in

\footnotetext{
${ }^{4}$ Root-Mean-Square (abbreviated rms) is a calculation that allows for the energy content to be calculated when there is distortion on the voltage or current. For a sinusoidal wave, the rms value is the peak value divided by $\sqrt{ } 2$.

${ }^{5}$ These other causes can include, for example, resonance conditions in equipment, including in particular the effect known as ferroresonance, a complicated nonlinear effect best understood as a chaos phenomenon.

${ }^{6}$ See, for example, “Overvoltages on the AEP 765-kV System, by Arthur Hausburg, Gregory Vassel, Gerald Stillman, Joel Charrow and Jorn Haarh" IEEE Transactions on Power Apparatus and Systems, Vol PAS-88, No 9, September 1969, pp 1329 - 1342, and "Switching Overvoltage Analysis and Air Clearance Design on the KEPCO 765 kV Double Circuit Transmission System, Jeong-Boo Kim, Eung-Bo Shim and Jeong-Woon Shim, IEEE Transactions on Power Delivery, Vol 15, No 1, January 2000, pp 381 - 386.
} 
any subsequent calculation would therefore be a matter of choice, were it not for the fact that most, perhaps all, operators of lines at these voltages use energy absorbing devices called arresters to limit the voltage. A reasonable value for the overvoltage controlled by arresters is 1.5 times the nominal value. $^{7}$

It appears that factors higher than this have been extracted by NERC from IEEE 516, though it is not clear what use is made of them. For example, page 31 of the NERC draft (Exhibit A) has a table showing the transient overvoltage factors of various lines. The values range from 2.0 for a $765-\mathrm{kV}$ line to 3.0 for lines at $345 \mathrm{kV}$ and below. The Table states that the "Clearance (ft) Gallet (wet) @3000 ft" for a $765-\mathrm{kV}$ line is $14.36 \mathrm{ft}$. In fact, the Gallet equation, corrected for altitude, gives about $16.5 \mathrm{ft}$ for the specified level of overvoltage. It is also worth noting that the Gallet equation is typically applied to wet and dry conditions, as for an air-gap the withstand is the same whether or not it is raining. The presence of rain affects only the performance of insulator strings (see the Red Book, "Effects of Rain," page 530). ${ }^{9}$

We may observe also that the Technical Guide has an oversight on the matter. It opts for a value of 1.4 for lines $362 \mathrm{kV}$ and above, and 2.0 for lines $302 \mathrm{kV}$ and below (see page 41). The reader is given no rule in this part of Exhibit for any of the thousands of miles of line in the US at $345 \mathrm{kV}$.

Apart from correcting the oversight (ie, furnishing a value for $345-\mathrm{kV}$ lines) this reviewer would suggest a value of 1.5 (instead of 1.4) for the EHV-class lines unless the line design value is known to be lower. That may be a minor change, but would be in keeping with normal practice.

\subsection{Weather}

While we noted above that the presence of rain does not change the withstand of a large air gap, there is no doubt that weather is a major factor in the performance of overhead lines. When the weather is hot, a heavily-loaded line may sag. When the weather is windy, a heavily-loaded line may be cooled so it sags less, but it may be blown sideways towards an edge of the right-of-way. The NERC documents do seem to allow for these factors, though (since it was not the main charge of this review) the details have not been part of the study.

The probability of flashover is also affected by some aspects of the weather (such as humidity and air pressure), and these effects can be accounted for appropriately by using the results of the considerable amount of full-scale research into the topic. The Gallet equation is, in principle, one way to include an accounting for these effects. That is the topic of the next section.

\footnotetext{
${ }^{7}$ See, for example, “765-kV Station Insulation Coordination” by James Phelps, P.S. Pugh and James Beehler, IEEE Transaction on Power Apparatus and Systems, Vol PAS-88, No 9, September 1969, pp 1377 - 1382.

${ }^{8}$ Red Book: the full title is “Transmission Line Reference Book: $345 \mathrm{kV}$ and Above.” It was published in 1975 by EPRI, the Electric Power Research Institute.

${ }^{9}$ It is observed a few pages earlier that the flashover voltage for a given path in air is increased for an increase in air density or humidity. That statement makes it hard to understand why the "wet" description is used in the NERC Table.
} 


\subsection{Probability and Gallet}

Given that the NERC clearances are to allow for overvoltage, and given that the overvoltage factor is specified, all that remains is to determine the clearance required to reduce the probability of flashover to an acceptable level.

It is simple to express the problem, but not so easy to solve it. At its root, the problem is very similar to the problem faced by the designers of the power lines themselves. That question is discussed at length in Appendix A. Briefly, for the large gaps needed to insulate high-voltage power lines, the relationship between the gap and the voltage withstand capability is extremely nonlinear, and very variable. While the principles of gas breakdown for small gaps and fields that are nearly uniform are well understood, the effects that can occur in large gaps are not predictable. The designer has to rely on gathering statistics that describe the behavior of a variety of gaps under a variety of conditions.

The research to gather such information is very costly and very time-consuming. While the work was undertaken in laboratories around the world, it was accompanied by a desire to substitute some analytical way of predicting performance, rather than simply describing it. Most of the researchers attempted to find ways to fit curves to their measured results.

Many such curves were fit by many computer programs, with varying amounts of success. None of the methods was based on a physical understanding of the processes of large-gap breakdown. ${ }^{10}$ Instead, all were based on hunches about what kind of curve would fit the data. One of the equations was the one described by Gallet in his 1975 paper. The equation he gave was

$$
U=k \cdot \frac{3.4}{1+\frac{8}{d}}
$$

Where $U$ is the critical sparkover voltage in MV, and $d$ is the gap in meters. The constant $k$ is called the gap factor.

There are two things to observe.

1) The value obtained is the value for what is usually called the critical flashover voltage, or CFO. This term is explained in the glossary, and examined in detail in Appendix A of this report. For now, we may note that the value for CFO corresponds to a 50\% probability that there will be a flashover when the gap in question is subject to a positive impulse whose peak value is given by $U$.

\footnotetext{
${ }^{10}$ There is a single exception to this statement. In the years following the most active period of UHV research, the author of this review, working at the AEP UHV station in Indiana, and in collaboration with Dr W.J. Gajda of the University of Notre Dame, developed an equation based on breakdown physics to describe the audible noise of a power line in rain. This was highly successful, in part because the scale of the problem was of the order of cm, not the meters involved in tower design. See A mathematical model of transmission line audible noise - Part 1:

Background and model development, Kirkham, H. and Gajda, W.J., IEEE Trans. Power Apparatus and Systems, Vol 102, No 3, March 1983, pp 710-717, and A mathematical model of transmission line audible noise - Part 2: Comparison with experiment, Kirkham, H. and Gajda, W.J., IEEE Trans. Power Apparatus and Systems, Vol 102, No 3, March 1983, pp 718-728. This model was incorporated by Electricité de France into their line-design code.
} 
2) With $k=1$, the "gap in question" is the gap between a rod and the ground plane. For any other gap, the value of $k$ must be known.

On its face, the equation is of limited usefulness. However, it is mathematically simple and it has been adopted fairly widely as being representative of the breakdown of large gaps. Some examples are given in Appendix A.

For our purposes in considering vegetation clearances, there are two things to consider. First, we need to understand how to obtain a much lower flashover probability than the $50 \%$ value that is $\mathrm{CFO}$. The NERC document, for example, observes that "When the Gallet Equation and conservative probabilistic methods are combined, i.e. deterministic design, spark-over probabilities of $10^{-6}$ or less are achieved." Second, we need to understand how to relate rod-plane clearances to vegetation clearances. We examine these two topics next.

\subsubsection{Flashover Probability}

The process of flashover between two electrodes separated by a large gap is highly variable. The way this variability was dealt with in the research that led to the writing of the Gallet equation was that a large number of tests were performed, and some kind of statistical processing done.

Since the process of flashing over an air gap with an impulse is "self-healing" in that the arc stops rapidly and the ionized air drifts away rapidly, the gap can be repeatedly caused to flash over without markedly changing its characteristics. (The same is not true of solid-insulation testing.) Each flashover is called a shot, possibly because of the noise it makes. The method would proceed as follows.

First, a series of tests would be done to find the surge risetime that gave the minimum flashover voltage. This time corresponded to the "critical” value for the gap.

Then with that risetime, more shots would be done to establish flashover probabilities for various voltages. For the same gap, the surge voltage would be changed, and for each another series of shots run to produce another data point. An example taken from the Edison Electric Institute publication "EHV Transmission Line Reference Book" published in 1968 is reproduced here as Figure 1. The figure appears as Figure 6.44 of that document. ${ }^{11}$

Figure 1 presents results for a tower window, and shows that the curve for a rod-plane gap has a lower voltage for flashover at all gap spacings. (The dashed lines in the figure are lines drawn at voltages corresponding to $\pm 10 \%$ of the fitted curve.)

\footnotetext{
${ }^{11}$ This book is commonly called the Blue Book, in contrast with the later Red Book. By the time of the Red Book publication, EPRI was sponsoring UHV research, at the same facility established under EEI auspices in Massachusetts.
} 


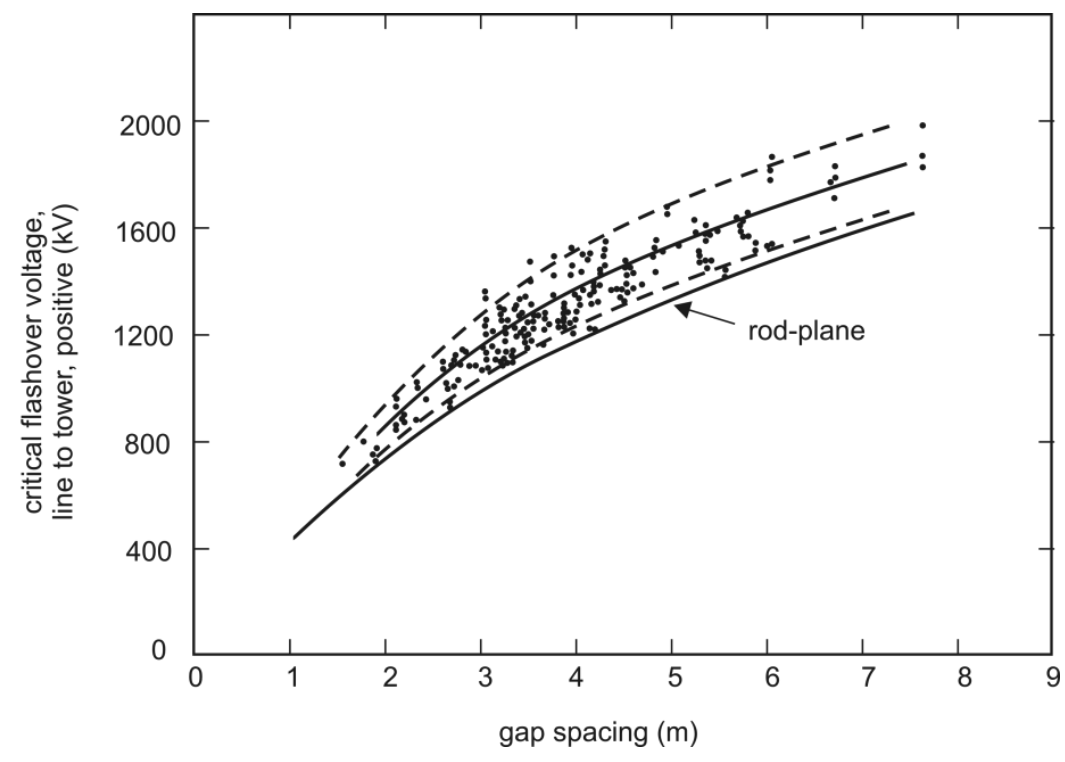

Figure 1 CFO voltage as a function of gap spacing (representative)

Very often, the processing was simple averaging: a large number of "shots" under the same gap and voltage conditions were averaged to produce a single data point representing a given surge voltage and a given gap.

All these runs, each with multiple shots, would then be used to produce a graph of flashover probability as a function of voltage for a given gap. An example is given in Figure 2, adapted from the Blue Book, Figure 6.36.

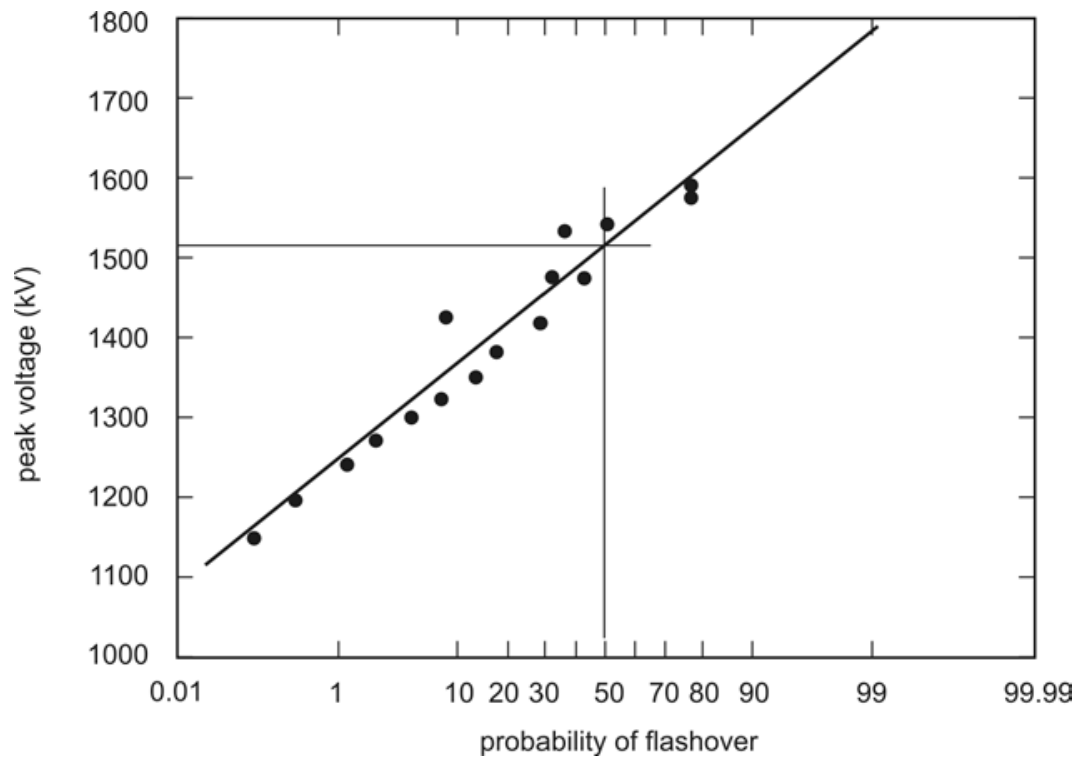

Figure 2 Representative flashover probability data. 
Each dot in Figure 2 may represent as many as 100 shots. The whole data set represents many weeks of work. From this work (and graphs such as this) it is possible to say that for a given gap if the $50 \%$ CFO is some particular value, the voltage for other probabilities can be estimated. Here a $50 \%$ flashover probability exists at about $1.51 \mathrm{MV}$, and the probability drops to $1 \%$ at about $1.25 \mathrm{MV}$.

It is fortunate that the line is straight on probability graph paper. The fact is that much of the time the experimental data would not really support a straight line. This problem is discussed in Appendix A. However, with a straight line, we can make an important assertion: the distribution is a Gaussian one. ${ }^{12}$ With that assertion, and a batch of experimental results, we can make the assumption that the standard deviation is $5 \% .^{13}$

With these two assumptions, we can stipulate that the probability of flashover drops to a reasonable value if we drop the voltage to $85 \%$ of the CFO value. $85 \%$ is $15 \%$ down on the CFO value, and $15 \%$ is three times the standard deviation. With a Gaussian distribution, the probability at three standard deviations below the center of the distribution is $0.13 \%$, not $50 \%$.

\subsubsection{Multiple gaps}

It must be noted that the probability just calculated is for one gap. In the testing for tower designs, one tower is typically built (or approximated with various structural and non-structural elements) and tested. From the results for one tower, the performance of a line with many towers can be calculated.

If there are several gaps, typically tower windows, and if each has the same probability of flashing over, the total probability of a flashover increases, although the probability at any one does not change. The calculation is not difficult, though it depends on the assumption of a normal distribution. ${ }^{14}$

If the probability of withstand (note that we use withstand probability here, not flashover probability) is written $P_{1}$ for a single gap and $P_{\mathrm{N}}$ for $N$ gaps in parallel, then we find the following relationship holds:

$$
P_{N}=\left(P_{1}\right)^{N}
$$

A worked example will be instructive: if there is a single gap with a probability of flashover of $0.2 \%$, the probability of withstand of 20 such gaps is $(0.98)^{20}$, which is 0.67 or $67 \%$. In other words, there is a one-third chance of flashover with 20 gaps in parallel.

\footnotetext{
${ }^{12}$ The Gaussian distribution (also called the normal distribution) is a mathematical description of the likelihood that a variable will have a particular value. It is the distribution that produces the well-known bell-curve. The distribution is described by two parameters: the mean and the variance. The mean is a measure of location (it tells where the center of the distribution is) and the variance is a measure of the dispersion (it tells how spread out the variables are. The standard deviation is a value given by the square-root of the variance.

${ }^{13}$ One of the reasons that the CFO value is used to specify gap performance is precisely that the standard deviation is not constant. The standard deviation has a minimum value around the CFO value.

${ }^{14}$ The behavior of a gap in the vicinity of the CFO is evidently normal, for all practical purposes. At the extremely low levels of probability that are of interest in tower window design (or vegetation clearance) the insulation performance is simply not well characterized. If the probability of a flashover is on the order of $0.01 \%$, it would take weeks of testing to establish even one single data point on a distribution. Because of the cost, the testing is not done down to extremely small probabilities: instead, an assumed distribution is used in analysis.
} 
The Blue Book provides a convenient chart for assessing the impact of multiple gaps (see Figure 6.37). An adaptation of it, showing the interaction of multiple gaps, amount below CFO and withstand probability, is given here as Figure 3.

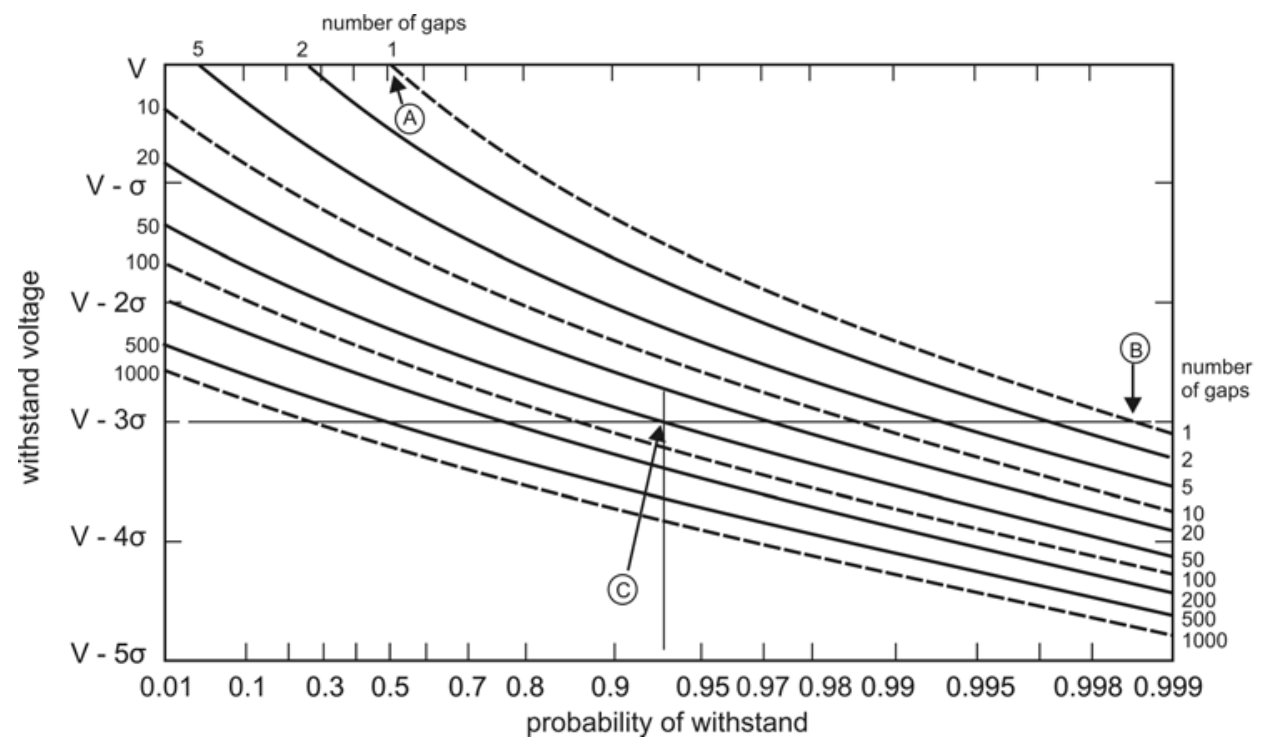

Figure 3 Withstand probability for multiple gaps

In Figure 3 the withstand voltage for a single gap at a probability of 0.5 is $V$, the CFO, point $\mathrm{A}$. The same single gap probability with the voltage reduced by three standard deviations $(V-3 \sigma)$ can be read off the graph at point B: it is between 0.998 and 0.999. (We know from the earlier analysis that the value must be $(1-0.0013)$ or 0.9987 .) With 50 such gaps in parallel, the withstand probability drops below 0.95 , as indicated by the added lines at point $\mathrm{C}$.

In other words, the addition of 49 gaps has increased the chances of flashover to more than $5 \%$. The withstand capability could be restored to its single-gap value by reducing the voltage to something like $(V-4 \sigma)^{15}$

\subsubsection{Gallet: The inverse problem}

The Gallet equation was one of many equations invented to fit data obtained for UHV line design. ${ }^{16}$ It gave the $50 \%$ voltage withstand capability (the CFO) as a function of the gap between a rod and a

\footnotetext{
${ }^{15}$ Note that from a practical point of view, testing a single gap at $3 \sigma$ or $4 \sigma$ is challenging, because many thousands of shots would be required to obtain enough flashovers to give a statistically useful result. Therefore, the use of the CFO and the mathematical adjustment for $3 \sigma$ or below is much more practical.

${ }^{16}$ Another was found (several years before the publication by Gallet) by Luigi Paris in Italy. He proposed the use of $V=0.5 d^{0.6}$ where, as before, $d$ is the gap in meters and $V$ is the CFO in MV. See L. Paris and R. Cortina, Impulse Discharge Characteristics of Air gaps and Insulator Strings, IEEE Trans Power Apparatus and Systems, Vol PAS-87, No 4, April 1968, pp 947 - 957. The curve fits of Gallet and Paris are compared in Appendix A.
} 
plane. The vegetation clearance problem is the inverse of that: we can calculate the voltage we need to withstand, we then need to find the gap that is required. The Gallet equation contains all the information we need, but in the wrong form. Graphically, we need to flip things around. This has been done in Figure 4.

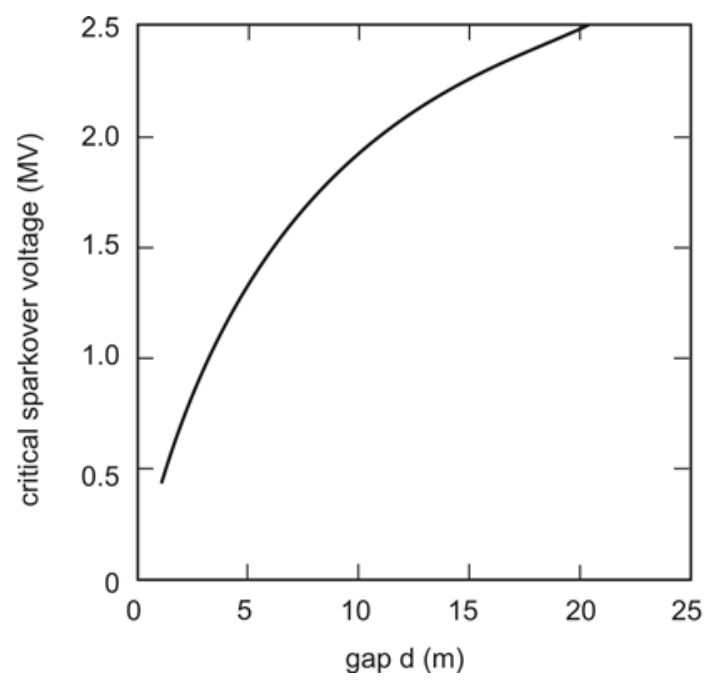

(a) The Gallet equation solved

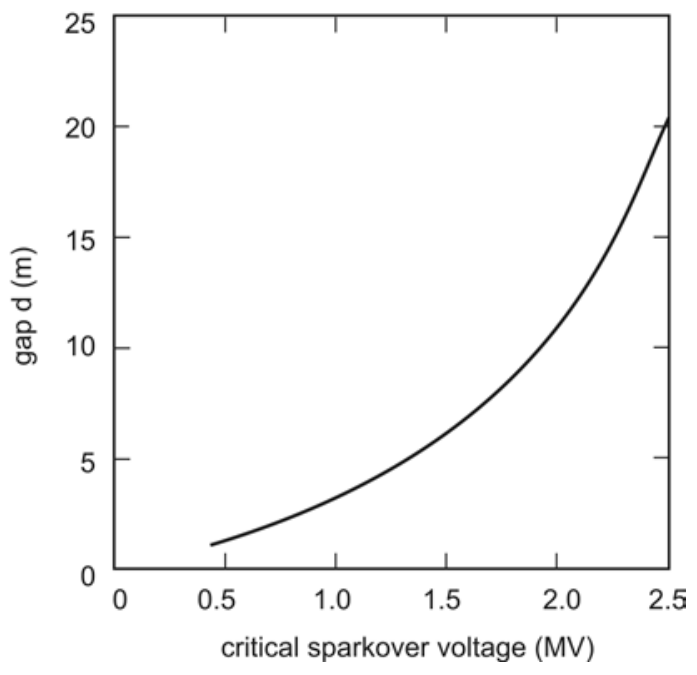

(b) the "flipped" solution

Figure 4 The Gallet curve, and a "flipped" version

For an EHV (or UHV) power line of any given voltage, the overvoltage is fixed by the line voltage and the surge arresters. If we take the example of a fictitious $550-\mathrm{kV}$ line used in the NERC Technical Reference document (Exhibit I, page 42), and if we allow the overvoltage factor to be 1.4, we find a voltage of $629 \mathrm{kV}$. (This is the number in the Technical Reference document, too.) We have no basis for knowing a gap factor, but if we ignore that for the moment we can calculate that if $85 \%$ of the CFO voltage is to be $629 \mathrm{kV}$, the CFO voltage must be $740 \mathrm{kV}$.

Examination of Figure 4 yields the information that for $740 \mathrm{kV}$ the gap must be about $2 \mathrm{~m}$. The same information can, of course, be found by inverting the Gallet equation ${ }^{17}$, or by doing our own curve fit to the curve shown in Figure 4(b). ${ }^{18}$

According to either of these methods, for $\mathrm{V}=740 \mathrm{kV}$, the gap is $2.2 \mathrm{~m}$. Note that this value is already bigger than the figure in the Technical Reference document (Exhibit I), in spite of the fact that we have made no allowance for altitude. (We have also not applied a gap factor.)

${ }^{17}$ Producing $d=\frac{8}{\left(\frac{3.4}{U}-1\right)}$, an equation that can be implemented on a spreadsheet.

${ }^{18}$ A suitable fit is the quadratic equation $d=2.6743 \mathrm{~V}^{2}-0.5515 \mathrm{~V}+1.1665$. This equation gives a value of $\mathrm{R}^{2}$ of 0.9997 over the range $0.7 \mathrm{MV}$ to $1.7 \mathrm{MV}$, meaning it is an excellent fit (99.97 of the variation in $d$ is explained by the equation.) 
We have no basis for choosing a gap factor of any particular value. The gap factor is a number that must be determined experimentally, and relates the withstand capability of a tower window to the withstand capability of a rod-plane gap.

If we use a gap factor of 1.3, as in the Technical Reference document, ${ }^{19}$ the assumption is that the gap we are dealing with could withstand 1.3 times more than the gap of a rod-plane with the same spacing. Normally, this would mean that to find the CFO voltage for a square tower window, for example, we can multiply the voltage of the rod-plane CFO by 1.3. If we had a rod-plane gap whose CFO is $740 \mathrm{kV}$, we could assert that a tower window of that size could be used up to $962 \mathrm{kV}$. The gap factor multiplies the voltage value.

There is no basis for reversing the process and asserting that a tree has a gap factor of 1.3 (or any other number) and therefore has a stronger withstand capability than a rod-plane gap. This seems nevertheless to have been done in the NERC white paper (See Exhibit I, Equation 9, page 42), where two such factors are used with the effect of reducing the size of the clearance gap. If anything, an argument based on the asymmetry of the electric field would suggest that a rod-plane gap and a tree branch might have about the same gap factor (ie, $k=1$ ). See Appendix B for discussion of field enhancement.

\subsubsection{Correction for Altitude}

Gallet's equation furnishes the value of the voltage for a given gap under standard atmospheric conditions. It has been known since the days of Paschen ${ }^{20}$ that a decrease in the gas pressure (such as would naturally accompany a higher altitude) resulted in a lower flashover voltage for small gaps. This result was demonstrated by Paschen at the relatively low voltages needed to break down gaps of a cm or so. By 1914 Peek had established that the effect was similar for the larger voltages needed to break down sphere gaps of a few tens of $\mathrm{cm}^{21}$ It is now accepted that the effect of altitude is always to reduce the withstand capability, and that the effect is (as with most features of high voltage work) nonlinear.

The method of dealing with the effect of altitude is almost always to start with the sea-level value and apply a correction. (This is simply because few high-voltage laboratories are built at high latitudes.) For the altitudes of interest here (up to, say, 10,000 ft), the correction may be as much as $2.6 \mathrm{ft}$ for an EHV line and $0.6 \mathrm{ft}$ for a lower voltage line. But note that the corrections factors are multiplicative: that is to say, the gap for a 10,000 ft altitude is expressed as the gap for sea level multiplied by a factor that ranges from 1.35 for an EHV line to 1.5 for a low voltage line.

\footnotetext{
${ }^{19}$ In Exhibit I, on page 39, it is asserted that this value is suitable for "line to large structure," a value evidently from reference 1 of the Exhibit. In fact, the number is found with that description on page 54 of the reference, where the large structure appears to be a house.

${ }^{20}$ Friedrich Paschen, Ueber die zumFunkenübergang in Luft, Wasserstoff und Kohlensaüre bei verscheidenen Druckenerforderliche Potentialdifferenz (On the flashover in air, hydrogen and carbon dioxide at various required applied potential difference). Wiedemann Annalen der Physik und Chemie, 1889, v. 37 pp. 69-96.

${ }^{21}$ F.W. Peek The Sphere Gap as a Means of Measuring High Voltage. Transactions AIEE Vol XXXIII, June 1914, pp. $923-949$
} 
The starting point for correcting for altitude is the Gallet solution: a matched pair of values for a gap and a CFO voltage valid for sea level and standard temperature and humidity. There are then two ways to apply a correction for altitude: either the voltage can be corrected (and a new gap calculated) or the gap can be corrected. Both methods appear in the literature.

If we use the Red Book correction for relative air density (Figure 11.13.3) to estimate the effect of going to $7000 \mathrm{ft}$ with the hypothetical line considered above (Exhibit I, page 42), we find for a gap of $2.2 \mathrm{~m}$ an exponent $n$ of 0.85 in the equation (Equation 11.13.4 in the Red Book):

or

$$
V_{S T D}=V_{T E S T}\left(\frac{1}{\delta}\right)^{n}
$$

$$
\frac{V_{T E S T}}{V_{S T D}}=\delta^{n}
$$

where $\delta$ is the relative air density (RAD). The ratio of the two voltages in this equation is a correction factor for voltage as a function of altitude. Assuming the temperature is unchanged (and at $7000 \mathrm{ft}$ that may not be fair), we can find $\mathrm{RAD}=0.77$ so that

$$
\frac{V_{T E S T}}{V_{S T D}}=0.77^{0.85}=0.8
$$

This is a statement that the voltage at altitude is allowed to be only 0.8 of the sea-level value before breakdown occurs. The correction factor for altitude is the reciprocal, about 1.25. That is, our earlier voltage of $740 \mathrm{kV}$ must be increased to about $925 \mathrm{kV}$. The Gallet equation, which operates on the peak of the overvoltage surge, gives a gap of $3 \mathrm{~m}$ for this voltage.

The Technical Reference document (Exhibit I, page 42-43) follows a method given by Hileman ${ }^{22}$ and regards this solution as iterative. Since the gap at the end of this calculation $(3 \mathrm{~m})$ is not the same as the $2.2 \mathrm{~m}$ starting one that allowed us to find $n$ (because the correction has been applied), the exponent $n$ is reevaluated for the new gap, and the calculation repeated.

Methods of correcting for altitude are surprisingly complex. Ordinarily one might turn to standards for guidance. Two relevant standards are the two standards for high voltage testing techniques, IEEE Std 4 (1995) and IEC 60060-1 (1989). They give complicated solution methods that are iterative or graphical (or both). For this review, we will simplify the matter by using correction factors found by examining the NERC work, based on the Hileman method. That is not to say that these corrections are exactly correct: merely that by using them we will obtain a way to compare results for each line voltage based simply on the sea-level values. For an altitude of $3000 \mathrm{ft}$, these correction factors (found simply by dividing the $3000 \mathrm{ft}$ entry - in Table 1, page 44 of Exhibit I - by the sea-level value), are given here in Table I, along with the correction in feet.

Table I. Factors used in NERC altitude corrections

\begin{tabular}{lcc}
\hline Nominal line & Correction Factor & Correction in feet \\
voltage $(\mathrm{kV})$ & at $3000 \mathrm{ft}$ & at $3000 \mathrm{ft}$ \\
\hline
\end{tabular}

\footnotetext{
${ }^{22}$ Andrew R. Hileman, Insulation Coordination for Power System, Marcel Dekker, New York, NY 1999
} 


\begin{tabular}{lll}
\hline 765 & 1.08 & \\
500 & 1.10 & 0.69 \\
345 & 1.11 & 0.51 \\
230 & 1.11 & 0.34 \\
115 & 1.12 & 0.33 \\
\hline
\end{tabular}

The table shows that the effect of altitude (at least, at $3000 \mathrm{ft}$ ) is to increase the required gap by about $10 \%$, a distance that is typically a few inches. With these factors, we can evaluate the various distances in the NERC documents. Table II compares the distances given as sparkover distances.

Table II. Comparison of sparkover distance values

\begin{tabular}{cccc|cc}
\hline \multicolumn{2}{c|}{ Sparkover distance, Exhibit A, P 31 } & \multicolumn{2}{c}{ Gallet } \\
\hline $\begin{array}{c}\text { Nom } \\
\text { voltage }\end{array}$ & $\begin{array}{c}\text { Max } \\
\text { voltage }\end{array}$ & $\begin{array}{c}\text { TOV } \\
\text { factor }\end{array}$ & $\begin{array}{c}\text { Clearance } \\
\text { at 3000 ft }\end{array}$ & $\begin{array}{c}\text { Same } \\
\text { assumptions }\end{array}$ & $\begin{array}{c}\text { At sea } \\
\text { level }\end{array}$ \\
\hline 765 & 800 & 2.0 & $\mathbf{1 4 . 3 6}$ & 16.5 & 15.2 \\
500 & 550 & 2.4 & $\mathbf{1 1 . 0}$ & 11.6 & 10.6 \\
345 & 362 & 3.0 & $\mathbf{8 . 5 5}$ & 9.6 & 8.7 \\
230 & 242 & 3.0 & $\mathbf{5 . 2 8}$ & 5.8 & 5.2 \\
115 & 121 & 3.0 & $\mathbf{2 . 4 6}$ & 2.7 & 2.4 \\
\hline
\end{tabular}

Table III compares the distances given as MVCD.

Table III. Comparison of MVCD values

\begin{tabular}{cccc|cc}
\hline \multicolumn{2}{c|}{ MVCD from Exhibit I, Table 1, p 44 } & \multicolumn{2}{c}{ Gallet } \\
\hline $\begin{array}{c}\text { Nom } \\
\text { voltage }\end{array}$ & $\begin{array}{c}\text { Max } \\
\text { voltage }\end{array}$ & $\begin{array}{c}\text { TOV } \\
\text { factor }\end{array}$ & $\begin{array}{c}\text { Clearance } \\
\text { at 3000 ft }\end{array}$ & $\begin{array}{c}\text { Same } \\
\text { assumptions }\end{array}$ & $\begin{array}{c}\text { At sea } \\
\text { level }\end{array}$ \\
\hline 765 & 800 & 1.4 & $\mathbf{8 . 8 9}$ & 10.5 & 9.7 \\
500 & 550 & 1.4 & $\mathbf{5 . 6 6}$ & 6.6 & 6.0 \\
345 & 362 & 2.0 & $\mathbf{3 . 5 3}$ & 6.1 & 5.5 \\
230 & 242 & 2.0 & $\mathbf{3 . 3 6}$ & 3.9 & 3.5 \\
115 & 121 & 2.0 & $\mathbf{1 . 6 1}$ & 1.8 & 1.6 \\
\hline
\end{tabular}

In these tables, the clearance values from the NERC filing are set in boldface. ${ }^{23}$ The numbers in the right two columns of each table have been added for reference. They were calculated using the inverseGallet equation in a spreadsheet. The altitude correction was identical to the one use by NERC, starting with the Gallet CFO value. That value is given in the right-most column.

In most of the cases here, the numbers given in each of the Exhibits are closer to the sea-level values than to the values for $3000 \mathrm{ft}$, but the agreement is not particularly good. Most of the values, in both tables, are actually smaller than the Gallet sea-level CFO values.

Notwithstanding the Gallet values shown here, it is certainly noteworthy that the numbers described as Minimum Vegetation Clearance Distance are about half the values shown as Sparkover Distance. This

${ }^{23}$ Where the table contains a column in italics, the data are not used in the calculation, though they are given in the document. For the sparkover distance, the max voltage is not used in the calculation, but the nominal voltage is. For the MVCD values, the nominal voltage is used instead, and the max voltage is not used. 
difference in values arises from the two different sets of assumptions behind the NERC calculations. The (larger) sparkover values come from a normal line-line voltage value and an inflated TOV factor. The (smaller) MVCD comes from a slightly inflated line-line voltage, and a somewhat low TOV factor. Both sets of NERC numbers include a gap factor of 1.3 in the calculation.

\subsubsection{Relation to Vegetation}

The assumption underlying the use of tower design data (and therefore the use of the Gallet equation) is that the large amount of information obtained by full-scale testing for tower design can be applied to the similar problem of vegetation clearance. What has not been demonstrated is that the tree problem relates to the rod-plane problem.

The matter can be put into perspective in the following way. Rod-plane testing is used in tower design because the rod-plane gap has a lower value of CFO than any other configuration of metal. The data in Figure 1 showed that all the flashovers required a higher voltage than the voltage indicated by the line identified as describing a rod-plane gap. A square tower window with a 3-m gap might, for example, have a CFO value $20 \%$ higher than a $3-\mathrm{m}$ rod-plane. (We would then say that the gap factor for that particular tower was 1.2.)

It has been found experimentally that tower window configurations require a higher voltage to flash over than the rod-plane of the same gap. That is to say, the gap factors are greater than unity. However, there is no reason to suppose that a gap factor of less than unity could not exist in the case of vegetation encroachment. That would mean that a flashover could take place at a lower voltage than for a rodplane gap of the same spacing.

This effect of electrode shape is crucial to gap performance, and the shape of growing vegetation is not something that is known in advance with any certainty. The rod in a rod-plane gap is customarily terminated by a half-sphere of the diameter of the rod. The subject of other shapes, primarily spheres of various diameters, was studied by a team at Hydro-Quebec, and they presented ${ }^{24}$ the results shown in Figure 5.

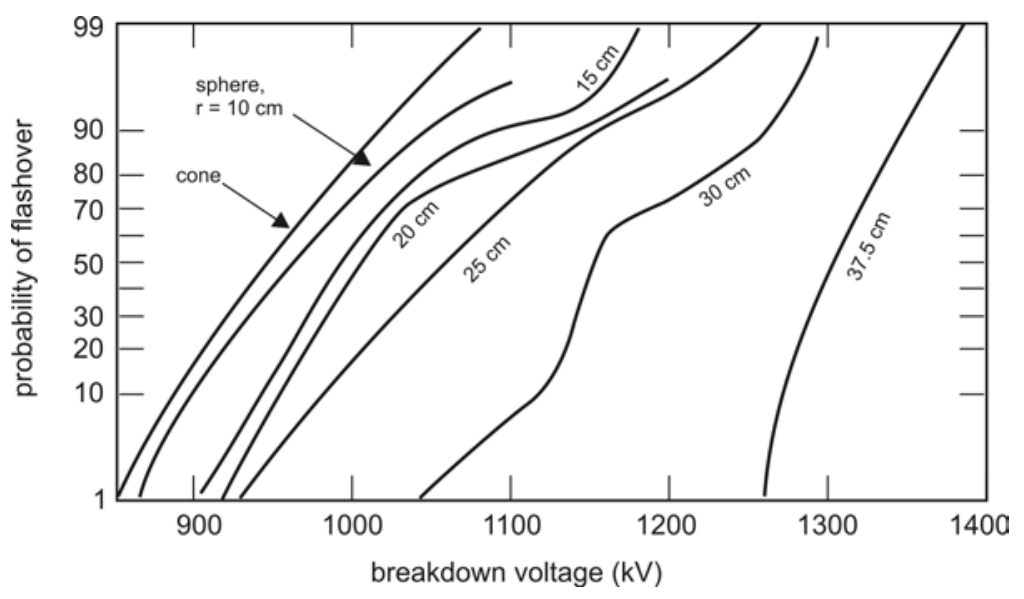

\footnotetext{
${ }^{24}$ Particularities of Air Insulation Behavior, C. Menemenlis and G. Harbec, IEEE Transactions on Power Apparatus and Systems, Vol PAS-95, No 6, Nov/Dec 1976, pp 1814 - 1822.
} 
Figure 5 Effect of shape of rod-end on withstand capability

Note that the results are shown here as they were in the paper: with the voltage as the abscissa, and the probability as the ordinate. The cone-ended shape on the left is therefore the worst. Other ends to the rod are better, by an amount that is strongly shape-dependent.

Whether a growing plant resembles a cone or a sphere, and whether a line resembles a plane are matters for discussion. All one can say with any certainty is that the breakdown voltage curves are very shape dependent.

\subsection{Vegetation Growth}

The matter of vegetation growth in the vicinity of power lines has been extensively studied. The usual goal of such work was to see if there were harmful effects on crops. Such work is very difficult, because factors such as soil drainage and composition can vary over the distance of a single span of a power line, and can also affect crop yield.

Some observations have been made and are reported in the Red Book. The concern in the Red Book was associated with the potential to start fires in wood adjacent to UHV power lines. The wood could be in the form of trees (living), trees (dead) and wood poles. At Project UHV, where most of the data for the Red Book were obtained, all three kinds of situations existed. Fires were observed only in nonliving wood.

The reasons offered for the immunity of living trees was that the trees are well-grounded through the sap, and therefore the current flowing through them because of the electric field in which they were growing was associated with little power loss, and therefore no appreciable heating. With dead wood, the resistance to current flow was higher, and the power loss (and heating) greater.

Our concern here is with flashover, not fire. The Red Book offers the following useful comment:

Trees may grow near a transmission line until they reach flashover or until local corona retards their growth. ... This is actually beneficial, a self-pruning effect, thus avoiding growth to flashover. Oak trees with round-edged leaves and blunt branch buds appear to grow to flashover without noticeable corona tip burning. Such trees do not show evidence of burning.

The reason that the shape of the growth is mentioned here is that the reader is expected to be aware of an effect known as field enhancement. A discussion of field enhancement is given in Appendix B. In brief, the electric field at the surface of a grounded object near a high voltage conductor is controlled by the voltage applied to the conductor, and also by the shape of the grounded object. Although the field without the grounded object present may be lower than that needed for breakdown, the effect of field enhancement may well cause the field to exceed the breakdown value locally. This is what is taking place at the surface of the conductor shown in Figure 8 (q.v.).

There is some similarity between the geometry of a rod-plane gap, and the geometry of a single branch growing toward a power line. But vegetation may (or may not) resemble a single-branch growth. A single branch would intensify the field in a manner similar to a rod. Multiple branches in the same 
vicinity would have the effect of shielding one another, and the maximum value of the field would be less intensified.

There is, however, a significant difference between the situation of a rod and a branch. The rod is a metal object, and removing electrons from its surface by means of an electric field is very difficult. The same is not true of a plant.

The early work on gas breakdown done by Paschen (see Section A.3 in Appendix A) took place in a regime of only moderate vacuum, because his pumps had limited capability. Today, we regard a vacuum as a good insulator because it is difficult to create a flashover in a hard vacuum. In air, free electrons are created by cosmic rays ionizing air molecules. These electrons are accelerated in the electric field to cause breakdown by ionizing more air molecules. In a hard vacuum, there are no free electrons, no air to ionize and no avalanche. Breakdown can take place only by pulling electrons off the surface of the metal. That takes a high-value electric field.

However, to pull electrons off the end of some vegetation may not require a very intense field. In fact, the end of the growing plant may appear to be burned. The writer of this report has seen this effect on corn growing in the high electric field near a UHV test line. The Red Book may be quoted:

Practical transmission-line electric fields may induce corona on the tips of plants. The presence or absence of this corona varies greatly with the shape of the plant and the space potential of induction. For example, an isolated cornstalk in a ground-level field of $10 \mathrm{kV} / \mathrm{m}$ will exhibit visible corona at the tassel and leaf tips.

The isolated cornstalk is not common, however, and the Red Book goes on to note that the proximity of other cornstalks has the effect of reducing the field. However, they make the observation that

Trees along a right-of-way may be damaged by corona ... Broad-leafed trees like oak are not damaged and will grow into a flashover condition ... [Black birch] trees were observed to die back short of flashover distances.

Whether the inhibitory effect of the field would take place at midspan, where the conductor position is less predictable than it is near the towers, is another matter.

\subsection{Summary and Conclusions}

NERC has proposed a standard to use to specify clearances between vegetation and power lines. The purpose of the rule is to reduce the probability of flashover to a calculably low level. The method proposed for calculating the clearances is based on the results of testing for high-voltage line designs. An equation developed in 1975 by G. Gallet of Electricité de France to relate the results of testing with rod-plane gaps to proposed tower window sizes has been adopted.

Much information is available from the research done for transmission line design. The Gallet equation arose during the performance of that research. It was a curve-fit, a way to reduce the amount of fullscale testing needed for the design of tower windows. The equation is based on the experimental 
observation that a metal rod-to-plane gap is the weakest (in terms of electrical strength) of all air insulation between metal objects.

No evidence is presented (or known) that would allow relating such a tower design method to vegetation clearances.

However, setting aside the appropriateness of adjusting the method to vegetation, the convenience of the method makes it worth considering. But the complete method must be considered. That means that all the factors that go into the estimate of the peak voltage must be included. It also must be remembered that the values of the voltage calculated by the equation are those that are $50 \%$ likely to result in a flashover. Because line designers do not design for such a high likelihood of flashover, the Gallet equation, if used, is not the end of the calculation. It is normal in the design process to reduce the voltage that can be allowed on a given gap to $85 \%$ of the Gallet value. That is 3-sigma lower than the center of the distribution, and gives a flashover probability of not $50 \%$ but $0.13 \%$. With some designs, an even lower value may be applicable.

In conclusion, it may be pointed out that the topic of the window size of towers of many designs have been extensively studied. However, there is not the same body of knowledge regarding vegetation clearance. Tower clearance values are nevertheless suggestive: the values for tower clearance for a line at $765 \mathrm{kV}$ in the Transmission Line Reference Book range from $14 \mathrm{ft}$ to over $18 \mathrm{ft}$. The NERC filing requires a gap less than $9 \mathrm{ft}$ for the same voltage, even at high altitude. There is no reason to suppose that a tree could safely be allowed so much closer to a line (less than $9 \mathrm{ft}$ ) than a tower. The goal of a calculably low probability of flashover would not be met. 


\section{Appendix A. Gallet and the Equation}

To assess the applicability of the Gallet equation, it is valuable to examine the context in which Gallet worked. Doing so will allow us to examine the motivation and the process behind the development of the equation, and will assist understanding its applicability. We must begin by turning the clock back to the 1970s.

\section{A.1 Historical Context}

The load on the electric power system of the US had been growing fairly consistently for the previous six decades or so, pushed in part by a growing population. Figure 6 shows the situation as it was known in 1970, with projections forward for about twenty years.

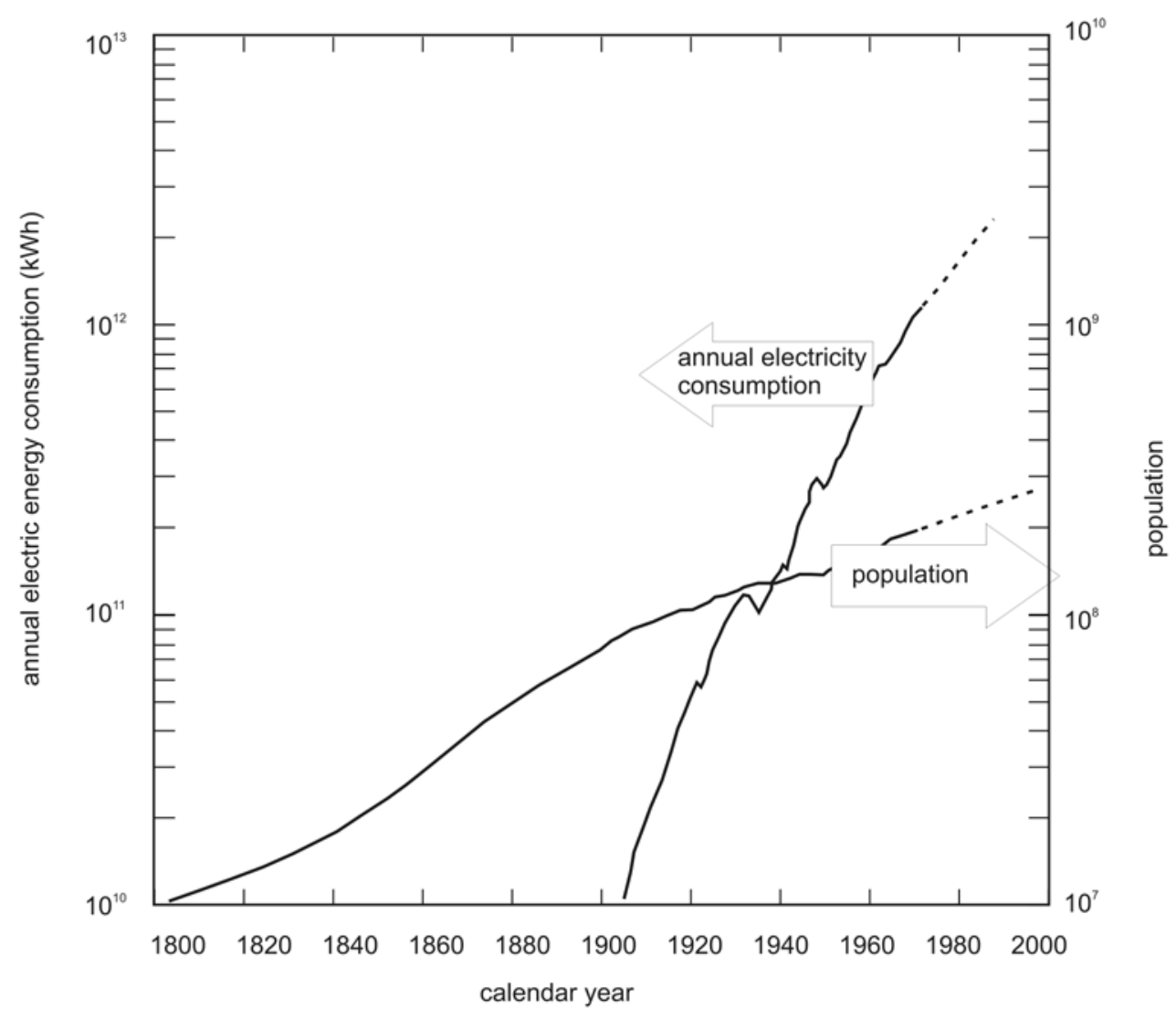

Figure 6 US Electric Load and Population Growth, 1800 - 1970

The continuing and rapid growth in electricity demand had led to an evolution in the way electricity was made and delivered. A system of ever-larger generators interconnected by power lines at everhigher voltage had been developed. A given system typically added an "overlay” of higher voltage every few years. The highest voltage in use at any time on a given system was typically more than twice what it had been prior to the addition of the overlay of the top level. A system operating at $138 \mathrm{kV}$ 
would be overlaid with lines at $345 \mathrm{kV}$, for example, and $230-\mathrm{kV}$ lines by $500-\mathrm{kV}$ ones. By the $1960 \mathrm{~s}$ $345-\mathrm{kV}$ lines were overlaid by lines at $735 \mathrm{kV}$ (in Canada) or $765 \mathrm{kV}$ (in the US). These levels were known as Extra High Voltage (EHV). Figure 7 shows the effect, with the US and the rest of the world alternately being the possessor of the highest voltage lines.

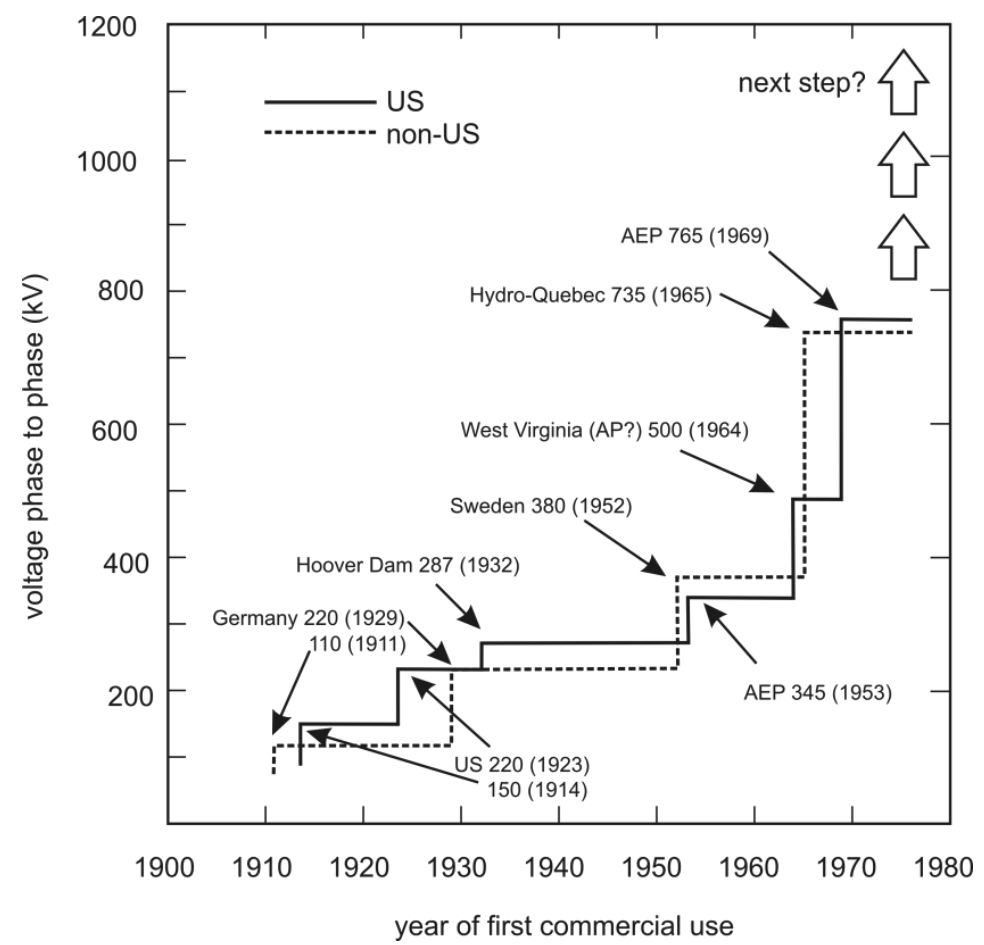

Figure 7 Highest voltage in use, US and elsewhere, 1900 - 1970

It was evident to some that at some time close to the end of the decade of the 1970s, the highest voltage would have to be again increased, to levels that came to be known as Ultra High Voltage, or UHV. Almost as soon as the 765-class lines were deployed, research began on the next level. Designers at utilities or at national research facilities developed a process for line design, including full-scale research.

\section{A.2 UHV Line Research}

In the design of a high-voltage power line, there are two aspects that must be considered. One is the design of the line itself - the conductors, their arrangement together (in what is called a "bundle"); and the design of the towers - the geometrical arrangement of the three phases, the size of the "windows" through which the lines must pass, the design of the corona rings at the suspension points, and the arrangement of the insulator strings.

To some extent the two aspects of the line design can be done separately, though in the end there are many interactions. The design of the line itself dominates the early considerations. In particular, the line 
must meet certain criteria in terms of its interaction with the environment. For example, it had been observed at lower voltages that power lines made radio noise and experienced power loss in rain. These effects were caused by the partial breakdown of the air insulation around the power line at high voltage. This breakdown, often called "corona” occurred at the tips of raindrops that were on the surface of the power-line conductors. Figure 8 shows an example of line design being tested for UHV. The conductors are arranged in a multi-conductor bundle, and are in a relatively small wire cage so that the electric stress at the surface can be made high with a relatively low applied voltage. The nighttime photograph shows many blue discharge points.

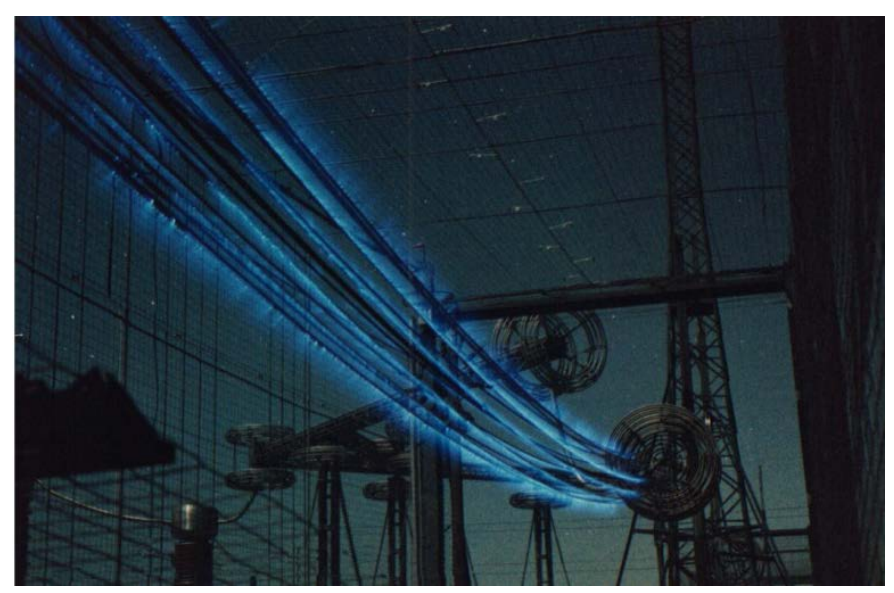

Figure 8 Power line in corona in a test cage

It was observed (apparently after the first 765-kV lines were built) that wet EHV lines could also produce audible noise in rain. The level of audible noise could be reduced by making the surface value of the electric field gradient lower. It is now evident that this aspect of the design of a power line dominates the bundle design.

What is taking place at the wet conductor surface is called "field intensification." Under dry conditions, the value of the electric field at the surface is perhaps $15 \mathrm{kV} / \mathrm{cm}$, around half the value needed to break down the air insulation. With water drops on the surface, the local field is distorted, and the shape of the drop is distorted. The end result is that the water drop becomes conical in shape, and the field at the tip of the cone is much higher than the value needed to break down the air insulation. The tip of the water drop goes into corona. Water is ejected (noisily) from the tip, along with heat loss and radio noise.

However, the field intensity falls off rapidly with distance from the conductor. As a result, the breakdown is limited to a region quite close to the surface.

To make the level of audible noise acceptable at UHV the local (near-surface) field is reduced by arranging the conductors in a configuration that may involve from six to perhaps as many as twenty 
sub-conductors. It is not hard to see that the more sub-conductors in the bundle, the more wind-loading the line will experience, and the stronger the tower must be. ${ }^{25}$

Once a line design is close, it becomes possible to examine options for the tower design. Unlike the situation on a line, the tower is a location where there is a possibility of complete (rather than partial) breakdown of the air insulation. At the tower, the line is in relatively close proximity to the (grounded) tower.

The question of the spacing between the two is the question that was being addressed by Gallet and other workers in the 1970s.

\section{A.3 Tower Design}

The breakdown of a gas in an electric field is a process that has been studied for over a century, beginning with the well-known work of Friedrich Paschen in the 1880s. Paschen investigated the breakdown of a gas for small gaps (a cm or less) between two metal spheres (also about a cm across), and discovered that there was an interaction between the pressure of the gas and the separation of the electrodes. It is now known that what he discovered can be attributed to the process known as an avalanche breakdown, involving the molecular mean free path and the velocity of electrons accelerated in the electric field. However, Paschen was working in Germany at a time when Dalton's atomic theory was not yet accepted, and so his work did not immediately advance understanding of the breakdown process.

It is now known that free electrons are available in any gas at "ordinary" pressures because of ionization by such things as cosmic rays or ultra-violet radiation. The motion of the electron in a gas is then controlled by the electric field and the interactions with the heavier molecules of gas. The electron reaches a drift velocity that can be calculated, and an energy level that may be enough to initiate an avalanche.

However, in a large gap, the local electric field is influenced by the presence of space charge, and that in turn is affected by the breakdown itself. The effects are extremely complex and nonlinear.

For example, because the masses of the electron and the molecule are so different, their mobility in the electric field is different, and positive and negative voltages have different effects. High-speed photography shows that the sparkover of a gap involves a streamer similar to the streamer seen in lightning. There are effects attributable to the risetime of the voltage, because the risetime of the electric field may be comparable with the transit time of the streamer in a gap.

\footnotetext{
${ }^{25}$ It is this aspect of the UHV line that has meant that no UHV lines have been put into operation in the US. It is generally accepted that the cost of the towers and the tower footings outweighs the savings in losses of the power line above about $765 \mathrm{kV}$. In a world where (for example) the cost of concrete is lower, or the need to keep the line noise below (say) $40 \mathrm{~dB}(\mathrm{~A}$ ) and the ground level field lower than (say) $8 \mathrm{kV} / \mathrm{m}$, UHV lines may be economic. But that does not seem to be our world.
} 
As gap dimensions become larger, the breakdown process becomes extremely nonlinear. Research showed that knowledge gained at lower voltages could not be extrapolated to higher voltage designs. The result is that although some of the breakdown physics is understood, the work of tower design has to be descriptive rather than prescriptive. Full-scale testing was essential.

By the 1970s, there were laboratories in Canada (most notably at Varennes, near Montreal, belonging to IREQ, the research arm of Hydro-Quebec), in Leatherhead, near London, belonging to CERL, the research arm of the Central Electric Generating Board, and at Les Renardières near Paris, owned by Electricité de France. In the US there were UHV research efforts under way in Pittsfield, MA, operated by General Electric for the Electric Power Research Institute, and in Vancouver, WA operated by Bonneville Power Administration. American Electric Power split their efforts between North Liberty, IN (line design) and Wadsworth, $\mathrm{OH}$ (tower design). The writer of this review was one of the team in North Liberty.

For tower design, most of the work concentrated on the likelihood of a sparkover when a switching surge occurred. When a line is switched, one or more current or voltage waves moves along the line. Called traveling waves, their reflection at the ends of the line can give rise to a doubling effect on the voltage. (The effect is used sometimes in generating very short pulses of known magnitude in pulsegenerator electronics.) For lines at low voltages, the voltage caused by a lightning strike will be higher in value than the switching surges, but for UHV lines it is certain that the switching-surge voltage will be higher than the lightning impulse voltage.

The voltage caused by lighting can be managed in two ways. The chances of a lightning strike can be reduced by the use of overhead grounded conductors (called ground wires) and the magnitude of the voltage controlled by maintaining a low tower footing resistance. But switching surges will occur because of the nature of switching, and any line design must be able to cope with that fact.

Impulse generators are used to produce simulated switching surges. A representative pulse shape is given in Figure 9. The risetime is typically a few hundred $\mu$ s, and the time to half-peak is a few ms. These times, along with the peak voltage, are frequently the parameters used to describe the impulse. For most testing, a positive impulse is used, as the breakdown voltage is lower for positive voltages than negative. (This difference results from the difference in mobilities of the positive and negative charge carriers.) 


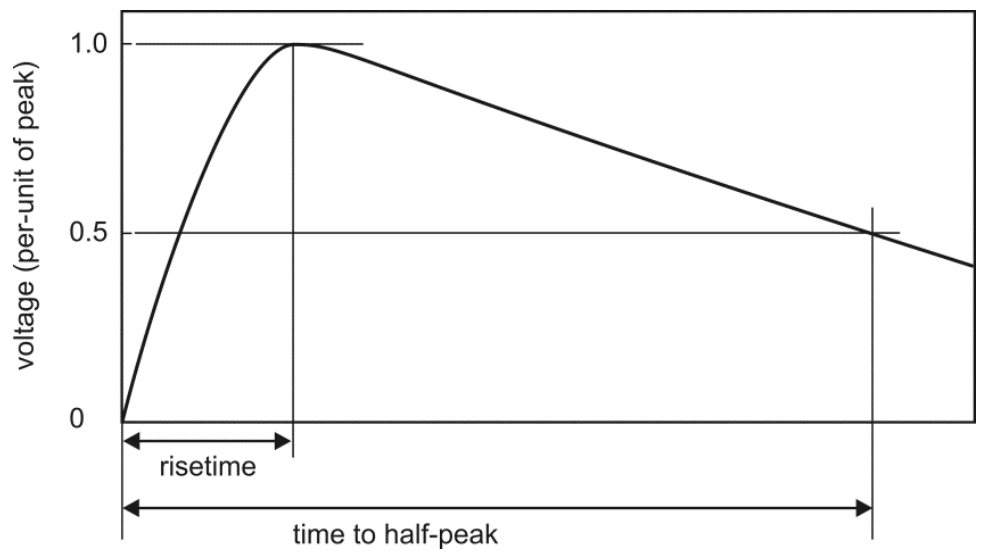

Figure 9 Representative impulse shape used in high voltage testing

By the 1970s, it was known that the chances of sparkover varied with the polarity and risetime of the impulse. Figure 10 shows representative results from a paper by the AEP group and the IREQ group.

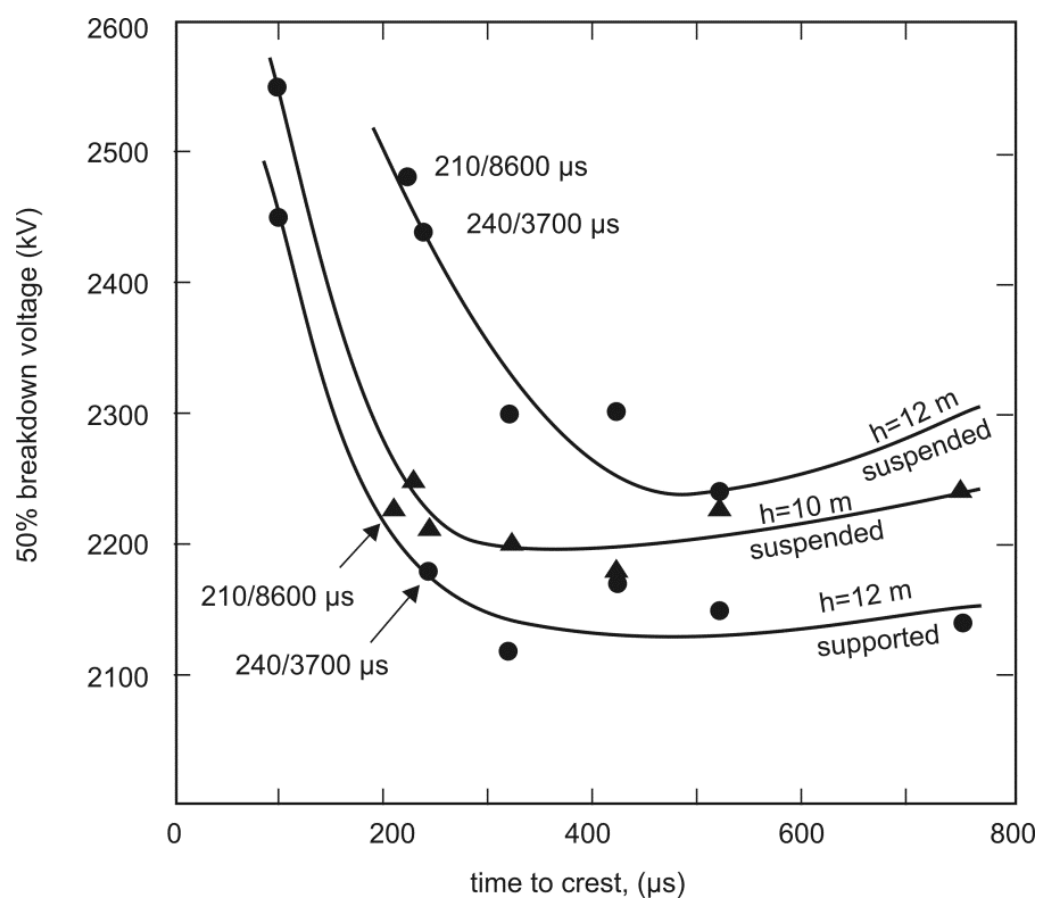

Figure 10 Variation of voltage withstand with pulse shape

Figure 10 shows the voltage at which the gap broke down 50\% of the time. It illustrates two things.

1) Although each data "point” represents many actual "shots," there is still a good deal of scatter.

2) The withstand curves for any given gap configuration show a definite minimum value as a function of the risetime. One may reasonably speculate that the risetime is close to the transit time of the streamer. 
The question of scatter is dealt with statistically. More data are taken, and processed (usually just averaged) to provide some smoothing of the curve. An example is given in Figure 11, which shows data from the IREQ laboratory. The data show that the voltage is lowest (furthest to the left) for a front time of $230 \mu \mathrm{s}$, and higher for both shorter and longer times.

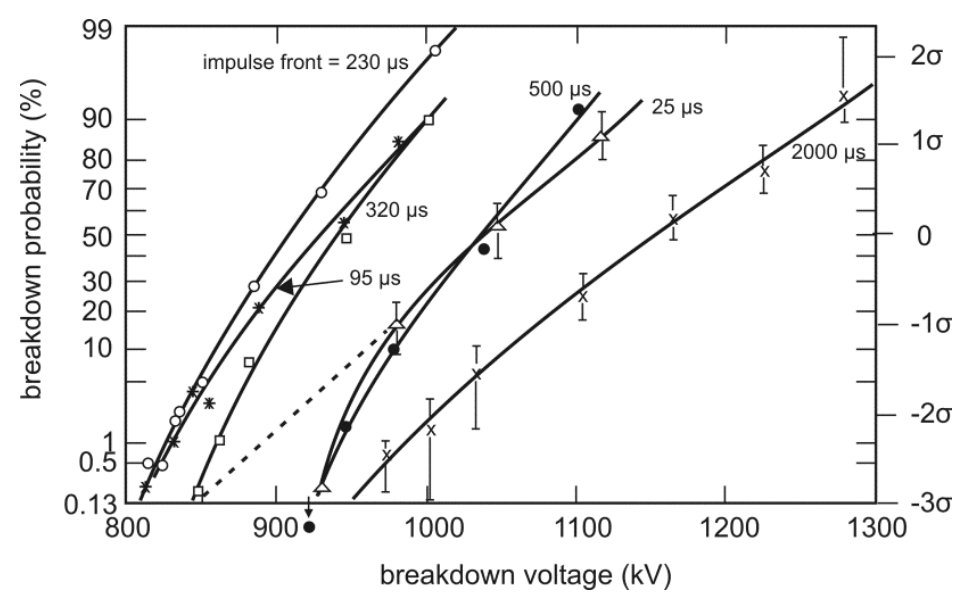

Figure 11 Breakdown probability for different impulse fronts

The question of the minimum time to flashover is dealt with by defining the voltage called the Critical Flashover voltage, usually abbreviated to CFO voltage. CFO is a sort of "worst case." The CFO is the voltage at the minimum of the curves of Figure 10 for any given configuration. ${ }^{26}$

The CFO of a given tower window is dependent on the number and type of insulators holding the conductor, on the material of the tower (wood or metal), on the clearances (including both the distance from the conductor to the tower and the use of corona rings at the suspension point) and on the weather. The exact influence of many of these variables is not well understood. There is therefore a need to use statistics.

\section{A.4 Nonlinearity and Saturation}

As voltages above a value of around $1 \mathrm{MV}$ were investigated, some workers (notably Aleksandrov in the Soviet Union, Paris in Italy, and Gallet in France) reported that there appeared to be considerable nonlinearity in the relation between the gap being tested and the voltage it could withstand. It was suspected by these researchers that there may be a saturation in the voltage that air insulation could withstand.

In the 1975 paper in which he presented the equation that is the subject of this report, Gallet made the following statement:

${ }^{26}$ In fact, the definition has changed over the years. Early on, it was customary to specify the voltage at which the flashover took place, usually on the rising edge, but sometimes on the falling slope. Eventually, it was found that more consistent results were obtained if the voltage at the peak of the impulse was specified, even if the flashover took place on the front of the pulse, and the peak was never actually attained. This is the current interpretation of CFO. 
With an overvoltage factor of 1.5 p.u. it would be impossible - from the dielectric point of view to build an A.C. network with a rated voltage higher than 2.4 MV (although an economic limit will probably appear at a much lower level).

We will examine this paper and its equation next.

\section{A.5 Discussion}

It was recognized by 1975 that the CFO values for various gaps were very dependent on the configuration of the gap. Work done earlier had shown that a "worst-case" gap was always the rodplane gap. For example, the EEI Blue Book included the graph shown here in Figure 12.

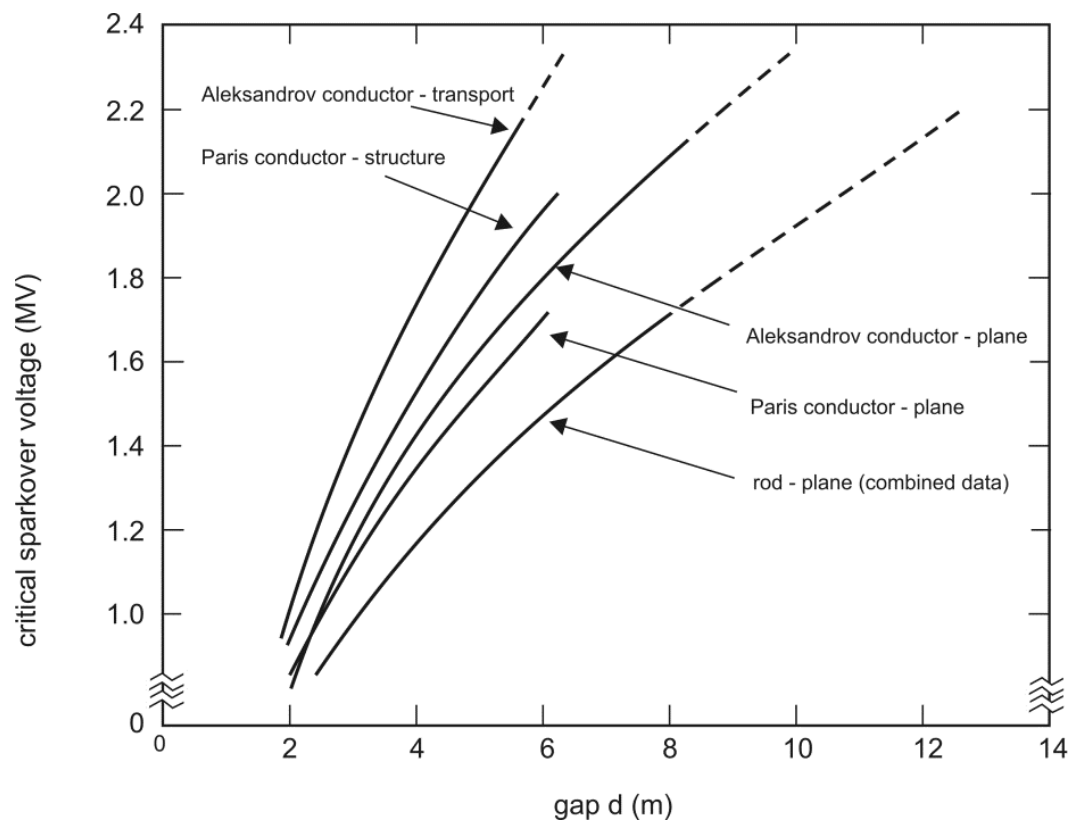

Figure 12 CFO values for a variety of gap configurations

Paris had found that the withstand capability of other gaps were often relatable to the rod-plane gap by a constant factor. He called the factor the "gap factor." The gap factor was something that had to be experimentally determined.

If it is accepted that the rod-plane gap is representative of all gaps, it follows that the rod-plane gap is the only gap that needs to be studied. ${ }^{27}$ Gallet therefore was concerned with producing an analytical representation of the rod-plane curve. In this he was successful.

${ }^{27}$ However, the fact is that the rod-plane curve does not apply directly to the situation of a tower window, and since there is no analytical way to calculate a gap factor in advance, knowing rod-plane data alone is not helpful in designing a tower window. 
In fact, one might speculate that he was too successful. His data and his curve were a very good fit. But the scatter shown on his data was remarkably small. Gallet's graph is shown in Figure 13.

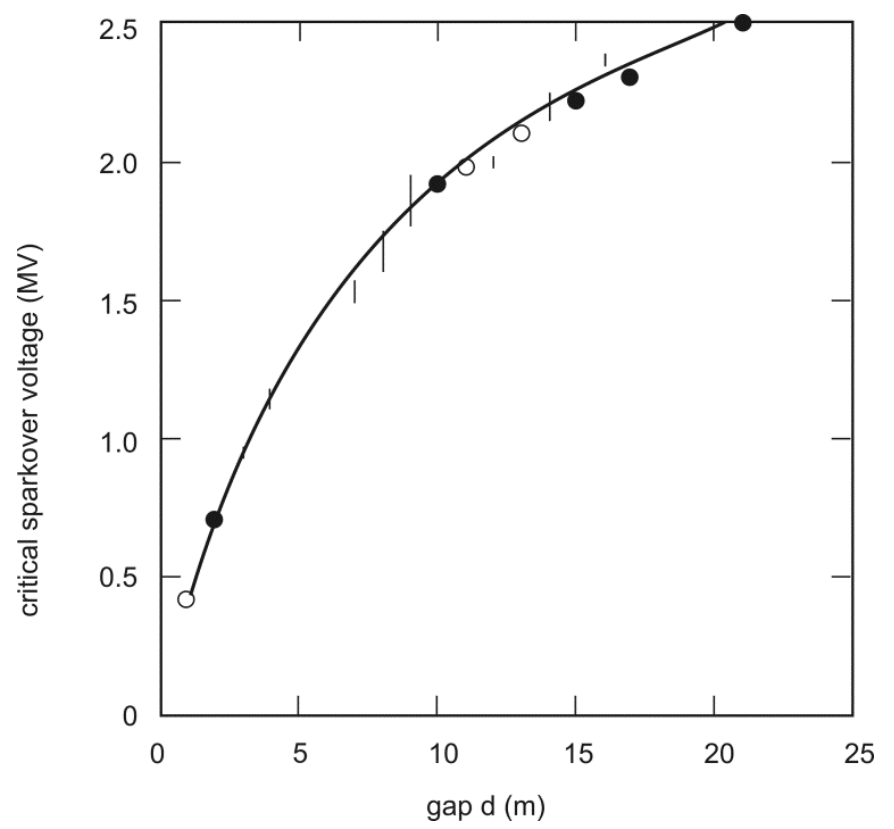

Figure 13 Gallet's curve supporting his equation

The curve is indeed a good fit to the data presented. The same can be said when the equation is shown on a graph from various other workers, such as the one given in the Blue Book. A combination of the Blue Book curve (Figure 12) and the Gallet curve (Figure 13) is given in Figure 14.

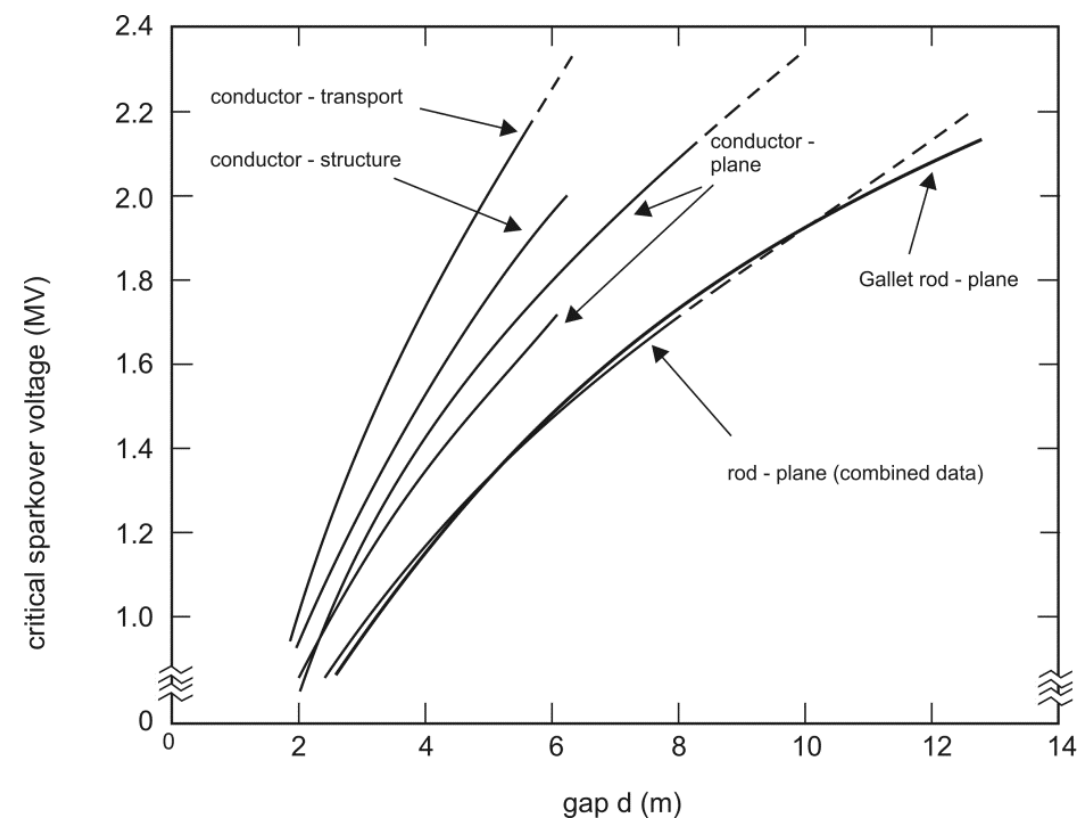

Figure 14 Gallet compared to Blue Book curves 
It is interesting to observe in Figure 14 that at gaps above about $10 \mathrm{~m}$, the Gallet equation shows a lower CFO value than the combined data shown in the Blue Book. It was because of this that Gallet was claiming there was saturation, and an ultimate limit to the withstand capability of the atmosphere.

The somewhat speculative nature of the findings can be seen when the curves of Gallet's equation and Paris's equation are fitted to a graph produced by Bill Pokorny and Bob Flugum. ${ }^{28}$ Pokorny and Flugum represented the AEP - Ohio Brass effort, and they were interested in showing that the new data from their work in Wadsworth, Ohio, extended the earlier work of several other laboratories, including (particularly) Project UHV. The pair produced a curve that combined the results of IREQ, EdF and Project UHV. In Figure 15 the writer of this report has added the Gallet equation and the Paris equation.

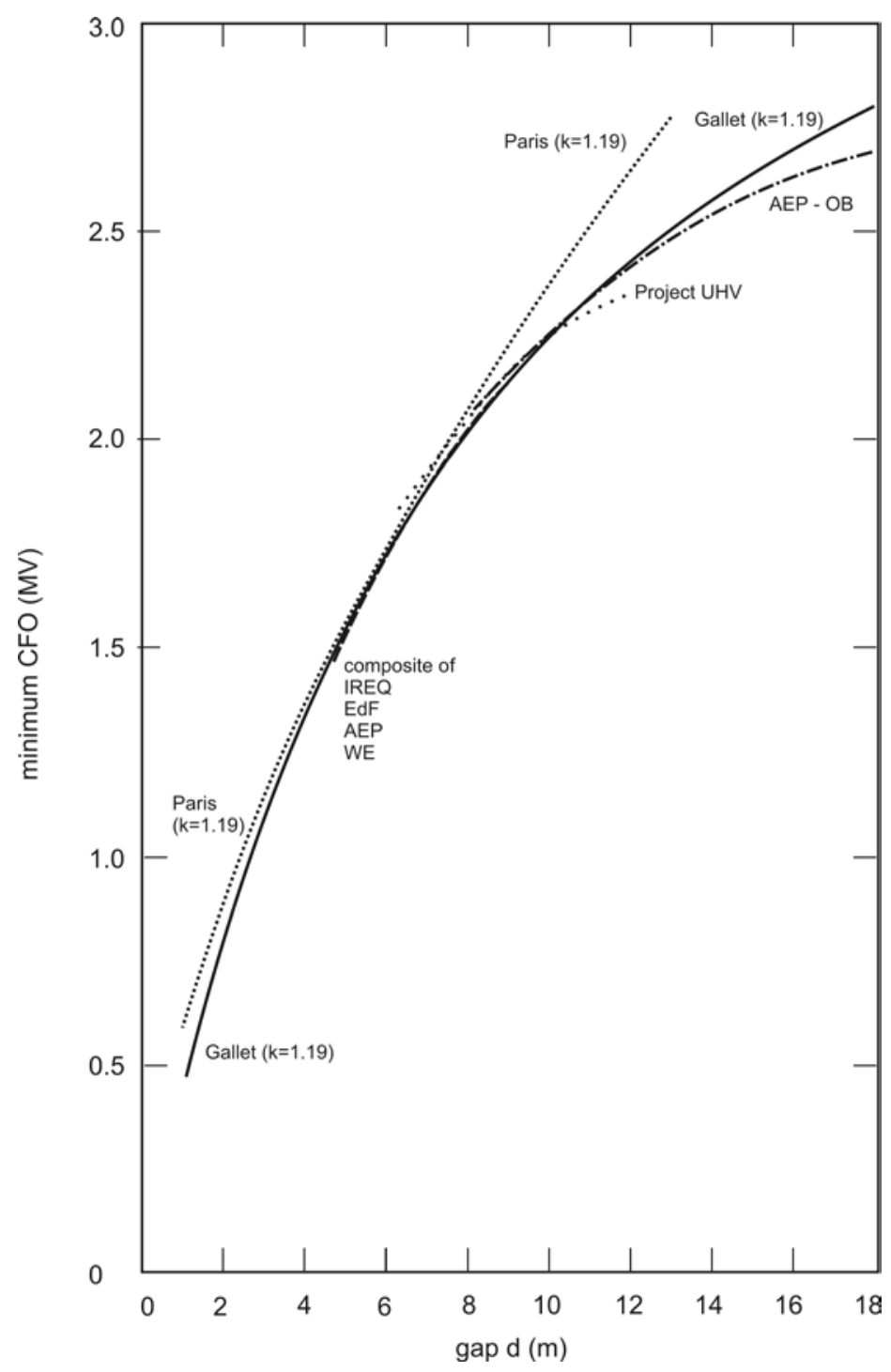

Figure 15 CFO curves from several laboratories, compared to Gallet and Paris with k= 1.19

\footnotetext{
${ }^{28}$ UHV Tower Insulation Parameters Determined by Full-Scale Testing, W.C. Pokorny and R.W. Flugum, IEEE Transactions on Power Apparatus and Systems, Vol PAS-94, No 2, March/April 1975, pp 518 - 531.
} 
A multiplying factor of 1.19 has been used (arbitrarily) with these two equations to make what appears to be a good fit. Note that the gaps whose test results are shown in Figure 15 are for a particular test configuration: a square tower window of half-width d, with a conductor $2.74 \mathrm{~m}(9 \mathrm{ft})$ from the ground. It is reasonably certain that not all laboratories tested exactly that configuration; the curves have been “adjusted.” The results do not include the small gaps included by Gallet, whose data set (for a rod-plane gap) went down to $1 \mathrm{~m}$.

The value of 1.19 for the multiplier of the curve shown in Figure 15 was found by graphical means. In his paper, Gallet finds the same value (to convert rod-plane results to tower-window estimates) by averaging a number of experimental tests on tower windows with $k$ values that he finds to be between 1.16 and 1.22 .

As it happens, the paper by Pokorny and Flugum and the paper by Gallet et al were presented at the same meeting, the Summer Meeting of IEEE Power Engineering Society in Anaheim, CA in 1974. In the US paper, the authors made some observations about gap factors that were commented on by the French team. In a discussion of the US paper, the French authors commented that

We don't think that the gap factor concept is only an approximation. We would rather say that the gap factor is a well-defined quantity for each geometry of electrode. Unfortunately, the actual poor knowledge of the breakdown phenomena prohibits the forecast of the value of an unknown structure, except by tests.

(The italics are mine.) The Gallet equation with $k=1$ is a reasonable fit to the rod-plane curve in Figure 14. Likely because of this, it was adopted by the EPRI Red Book. However, bearing in mind the comment by Gallet, it must be remembered that the value of the gap factor is something that must be determined by test.

The Red Book also gives curves comparing rod-plane results with tower window work. The graph is given here in Figure 16. 


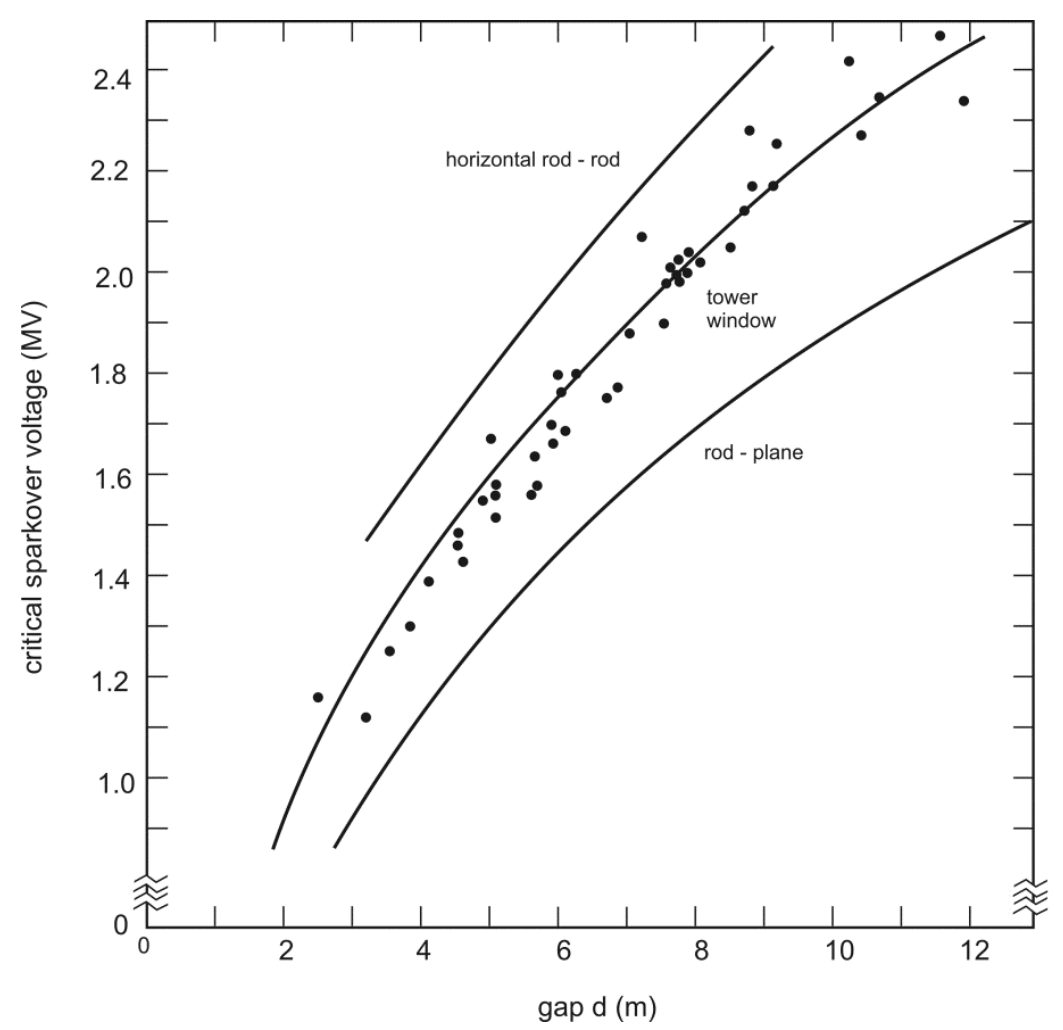

Figure 16 Red Book curve of tower window and rod-plane results

Curiously, the rod-plane results here are not those found by the Gallet equation. They appear to be offset by about $30 \mathrm{kV}$ : perhaps this is the result of a drafting error.

IEEE Standard 4 (High Voltage testing Techniques) also uses the equation. (See Section 4.1.2 of the 1995 version of the Standard. ${ }^{29}$ )

IEEE Standard 4 has two purposes in mind when discussing clearances. First, and most importantly from the point of view of a testing standard, it is necessary to reduce what are called proximity effects. Proximity effects are a change in the performance of an insulation system because of field distortion.

To achieve this end, the first suggestion in the standard is to have clearances that are equal to 1.5 times the length of the shortest possible discharge path on the test object. The Gallet value is then suggested as an alternative if smaller clearances are needed. The low rate of unintended flashovers is almost incidental.

IEEE Standard 4 also presents the idea of a withstand voltage being given by reducing the CFO voltage by three standard deviations. For convenience, a graph similar to the ones that appear here (beginning with Figure 4 ) is given in the IEEE Standard. On it, the $85 \%$ line $(3 \sigma)$ has been added under the CFO line.

${ }^{29}$ A new version of the Standard is presently being balloted. It is expected that it will be released in 2012. 


\section{Appendix B. Field Enhancement}

It is well-known that for small gaps, and at normal pressure and temperature, air breaks down at an electric field value of about $30 \mathrm{kV} / \mathrm{cm}$. In fact, while that is a useful thing to remember, air breakdown is a process involving several mechanisms, and is quite complex. Gaps smaller than $1 \mathrm{~cm}$ are stronger, and longer gaps are weaker in terms of the electric field needed for breakdown. The breakdown is also affected by the rate of change of the field with position, and partial breakdown may occur in situations where the local field exceeds a critical value, but the adjacent field does not.

The shape dependence is often described by an effect called field enhancement. The electric field may be enhanced by the way insulators are brought together or by the way conductors are inserted into previously more uniform fields. It is that effect that we will look at here.

The electric field between two flat parallel plates is calculable by dividing the voltage across them by the distance between them. ${ }^{30}$ If a conducting point is then sprouted up from one of them, the field at the tip of the point can be shown to be much larger than the undisturbed value. In fact, it is accepted among high-voltage engineers that the exact position of the remote (undistorted) plate plays almost no role in the enhancement. If one regards the field as having a certain value, created by a remote electrode at some unknown distance, the field at the point of a protrusion can be estimated based purely on its geometry. Figure 17 shows the result for two geometries.

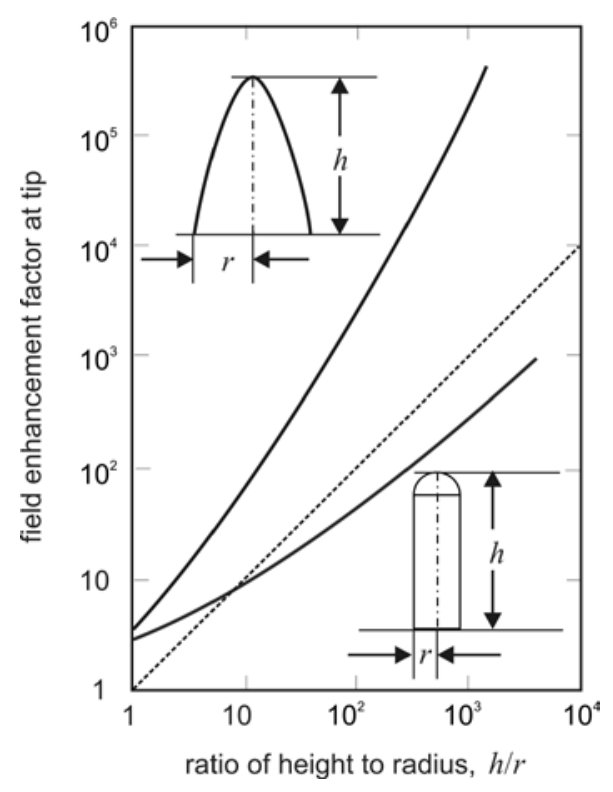

Figure 17 Field enhancement factors

For the rounded shape (a prolate spheroid) shown in Figure 17, the enhancement is greater than the ratio of height to radius. For the cylindrical shape, the two factors are closer. The effect is scale-independent.

${ }^{30}$ Ordinarily, the plates are assumed to be infinitely large, otherwise something must be done to control the field at their edges. That is a detail that need not concern us here. 
In high voltage engineering, the effect of distorting the field even without knowing the location of the remote electrode is sometimes used deliberately to create corona. For the purposes of generating a signal to check the operation of a partial-discharge measuring system, for example, a field can be set up and a needle inserted. Partial air breakdown will ensue if the enhanced field is above the breakdown threshold at the end of the needle.

Airplanes use this method. They are equipped with devices called "wicks" specifically to enhance the field to the breakdown value when the plane is in flight. If the plane becomes charged, as it will during almost any rain conditions ${ }^{31}$, the potential of the airplane body is large enough to create a field that can be enhanced to breakdown values at the tips of the wicks. The charge on the airplane is then leaked away via corona current, limiting the voltage of the airframe. Because of that, there is no large spark when the airplane lands. Figure 18 shows a wick on the winglet of a CRJ900. Other wicks can be seen at the bottom of the picture. They are on the wing itself.

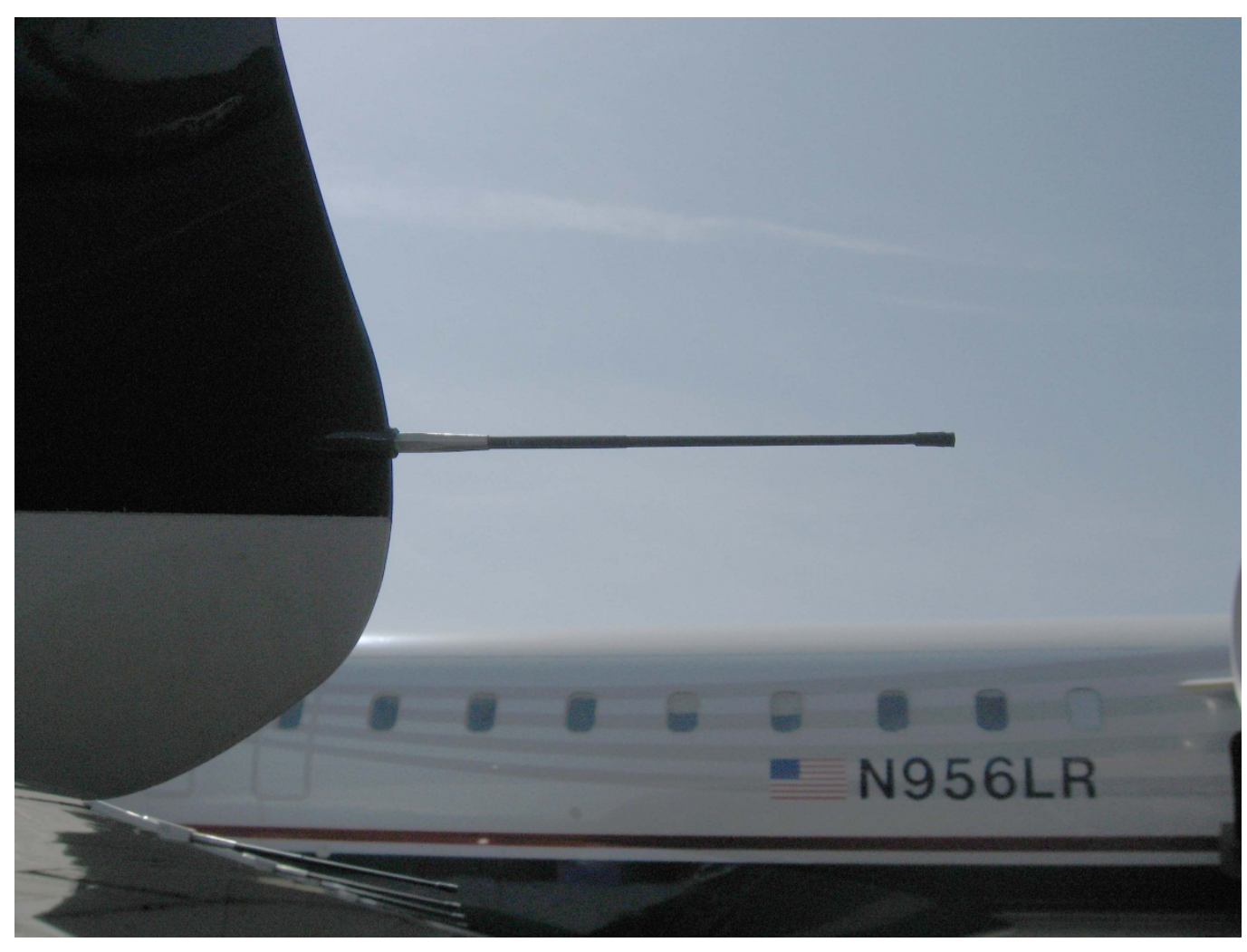

Figure 18 Wick on the winglet of an airplane

It is not hard to imagine that the electric field at the end of a growing plant in the vicinity of a power line will be enhanced. If it is enhanced sufficiently to cause local breakdown, there will be an abundance of charge carriers. There is every reason to suppose that flashover will be facilitated.

\footnotetext{
${ }^{31}$ The need to leak charge away from the airframe became evident during WWII, when planes were often flying in poor weather. Before wicks were invented, there was field enhancement on the radio antenna, and charge would leak off there. The problem was researched by the military primarily in order to improve communications.
} 


\section{Appendix C. About the Reviewer}

Harold Kirkham obtained a BSc degree (with specialization in both electric power systems and electrical measurements) and an MSc degree in power systems from the University of Aston in Birmingham, England. He then emigrated to the US, and worked for the Edison Electric Institute at their high voltage dc research facility in Philadelphia until it closed at the end of 1969.

He obtained a PhD from Drexel University in 1974, with the thesis "Control of HVdc system to stabilize an ac power system.”

Following his PhD, he worked for American Electric Power in their Electric Research Section, at first in New York and then in North Liberty, Indiana. In Indiana AEP had built a research station for ultrahigh voltage line design, in collaboration with ASEA (the company that later merged with Brown Boveri to become ABB). The AEP-ASEA UHV station investigated line designs up to the equivalent of 2.2 MV, and was equipped with a 1-km-long test line, and a pair of test cages for energizing conductors at relatively low levels (up to $650 \mathrm{kV}$ to ground) to achieve the surface electric fields of a UHV line.

In 1979, he left AEP and moved to the Jet Propulsion Laboratory in Pasadena, California, where for many years he managed a DOE project named Communication and Control for Electric Power Systems. Much of the work of the project was to do with power system measurements, and the team was the first to develop an instrument to measure the electric field of an HVdc power line, in air and without reference to the ground. This instrument allowed the measurement of the field near objects in the electric field. In 1989 he collaborated with ASEA in research (in the ASEA HV laboratory in Ludvika, Sweden) using this instrument to study the performance in rain of insulators at $600 \mathrm{kV}$.

After the DOE project closed at JPL, Dr Kirkham managed the Neptune power project, a scheme to bring power to science nodes operating at depth under the ocean on the Juan de Fuca tectonic plate. The team developed a power delivery system operating at $10 \mathrm{kV}$, and a dc/dc converter design to provide power at $400 \mathrm{~V}$ to the science nodes. He also joined the Mission Assurance Office of the Laboratory, where he set up a high voltage laboratory to measure the partial discharge performance of insulators subject to either ac or dc electric stress.

He left JPL in 2009 to come to the Pacific Northwest National Laboratory in Richland, WA, where he works mainly on a model of power system operations.

Dr Kirkham is a Fellow of IEEE, and a member of several societies within IEEE, for example the Power Engineering Society, the Dielectrics and Electric Insulation Society, and the Instrumentation and Measurements Society. He has worked on several IEEE standards. Of relevance to the present review is IEEE Std 4, the standard on high voltage testing techniques. Dr Kirkham was a member of the working group that released the new version of this standard for ballot in December 2011. 